\title{
Hybrid Alopex based DECRPSO algorithm optimized Fuzzy-PID controller for AGC
}

\author{
Jyoti Ranjan Nayak*, Binod Shaw* and Binod Kumar Sahu** \\ *Department of Electrical Engineering, National Institute of Technology, Raipur, Chhattisgarh 492010, India \\ **Department of Electrical Engineering, ITER, Siksha 'O'Anusandhan University, Bhubaneswar 751030, India \\ *Corresponding author: bapi.jyoti.2@gmail.com
}

\begin{abstract}
This paper corroborated the hybrid Alopex based Differential Evolution Craziness based Particle Swarm Optimization algorithm (ADECRPSO) over DE, ADE, PSO, and CRPSO algorithms to pursuit the gain parameters of the PID and Fuzzy PID (FPID) controller. In a two-area thermal-hydro-diesel power system, primacy of FPID controller is endorsed with PID controller tuned with assorted optimization techniques. The hybrid ADECRPSO algorithm is affirmed over the above mentioned algorithms to tune PID controller in a two-area hydro-thermal system. PSO, DE, CRPSO, ADE, and ADECRPSO are executed individually to optimize the controller to enhance the transient analysis by conceding undershoot, overshoot, and settling time of the system. The compilation of advantages of alopex based DE and craziness based PSO causes an adequate hybrid algorithm, which enhances the performance of Automatic Generation Control (AGC). The step load uprise in area-1 is imposed to observe the activities of AGC. Undeniably, FPID controller optimized by ADECRPSO commits superior performance over PSO, DE, CRPSO, and ADE optimized controller as proposed AGC system. The FPID controller optimized by ADECRPSO, ADE, and CRPSO is realized in real time environment (OPAL RT OP5600). So, the modified mutation of DE by alopex scheme enhances the potentiality to tune the system variables.
\end{abstract}

Keywords: Automatic Generation control (AGC); Craziness based PSO (CRPSO); Differential Evolution (DE); Fuzzy PID (FPID); Hybrid Alopex based Differential Evolution craziness based Particle Swarm Optimization (ADECRPSO) algorithm.

\section{INTRODUCTION}

Interconnection of the system is an imperative arrangement to attain the load demand growing with a brisk proportion. Interconnection enhances the stability, cost-effectiveness and also utilizes the generating stations sublimely. The prime function of the interconnected power system is to equipoise the power generated with the load demand associated with the loss (Kundur et al., 1994). Small load variation consequences the deviations of system frequency and power from alleged value and transmitted to other areas, which may cause abominable effects. To yield the power economically, stably, and reliably in interconnected power system, it is requisite to fix the system frequency and tie-line power deviations to their scheduled values (Kundur et al., 1994; Cohn, 1956; Fosha, 1970). AGC is a vital character to resolve the above problem. AGC acts as a secondary controller in the power system. This control mechanism is applicable to regulate the basic functions to:

i. Enhance the trait of transmitted power economically and reliably.

ii. Enhance the ability to impasse the deviations of frequency and tie-line power to zero (i.e. $\Delta \mathrm{f}=\Delta \mathrm{P}_{\text {tie }}=0$ ).

iii. Minimize the function concerning overshoot $\left(\mathrm{O}_{\mathrm{sh}}\right)$, undershoot $\left(\mathrm{U}_{\mathrm{sh}}\right)$ and settling time $\left(\mathrm{T}_{\mathrm{s}}\right)$. 
Many researchers have introduced lots of various controllers and optimization techniques to amend the performance of the AGC. Kumar et al. (2005) have highlighted the various control strategy adopted to enhance the performance of AGC for last few decades. Khodabakhshian et al. (2010) and Shabani et al. (2013) have proposed the PID controller as AGC of hydro power plant and a robust PID controller in a two-area interconnected power system optimized by ICA respectively. Intelligent cascade consolidation of PI-PD and 2-DOF PID enhances the performance of AGC over conventional PID controllers analyzed (Dash et al., 2016; 2014; Sahu et al., 2016). For last few decades many researchers have concluded the Fuzzy Logic Controller (FLC) as a predominant controller than other traditional controllers proposed by Zadeh (1965). The cascade aggregation of FLC and PID (FPID) optimized by various optimization techniques enhances the performance of the system, which is well described in Chown et al. (1997); Yesil et al. (2004); Nayak et al. (2015a; 2016; 2018b); Sahu et al. (2016); Sahu B.K. et al. $(2014 ; 2015 ; 2016)$. In Nayak et al. (2018a), cascade PD-FOPID optimized by GHS is validated. Many novel and hybrid optimization techniques have also been proposed like ABC, GWO, BA, PSO-PS, FA-PS, GS-PS, BF-PSO, and ASOS in (Gozde et al. (2012); Guha et al. (2016); Dash et al. (2015); Sahu et al. (2015a; 2015b; 2015c); Nanda et al. (2009); Nayak et al. (2018c). Kennedy et al. (1995) have introduced a swarm based technique entitled as PSO (Particle Swarm Optimization) and Ghosal (2004) has adopted this technique to improve the performance of AGC by optimizing the gain parameters of PID controllers. Panda et al. (2013) have composed BFOA (Bacteria Foraging Optimization Algorithm) and PSO to enhance the nonlinear power system. Storn et al. (1997) have introduced an evolutionary algorithm DE and Rout et al. (2013) have modeled AGC to analyze DE. Sahu et al. (2014) and Nayak et al. (2015b) have investigated the performance of FPID and T2FPID controller in AGC optimized by hybrid DEPSO algorithm proposed by Zhang et al. (2003). Hybrid DECRPSO algorithm is implemented to tune FPID controller in LFC Nayak et al. (2017).

In the present work, PID controller is adopted to validate the performance of the FPID controller of the system as AGC. The performance of the system is enormously influenced by the parameters of the controller. For the purpose to attain these parameters to enhance the system parameters, adoption of optimization technique is very imperative ingredient. PSO, craziness based PSO, DE, alopex based DE, and hybrid ABDECRPSO algorithms are adopted to tune the controller variables. The comparative analysis is concluded by implementing the proposed approach in three different power system models such as thermal-hydro-diesel, thermal-hydro, and thermal-hybrid power systems. The hybrid ABDECRPSO algorithm is concluded as better algorithm among the above-mentioned algorithms. The basic aspects of design of the proposed work are as follows:

1. To design power system model with thermal plant in area-1 and hydro-diesel plant in area-2.

2. To design the controllers to be imposed in each area.

3. To design optimum controller by adopting convenient optimization techniques.

\section{SYSTEM INVESTIGATED}

The explored system is a two-area non-reheat thermal-hydro-diesel power system. Areal is owing equivalent transfer function blocks of non-reheat thermal power station and area-2 is owning hydro and diesel power stations equivalent model as portrayed in Fig. 1. The power system parameters are expressed in appendix-1. Area Control Errors (ACEs) concerning deviations in frequency and tie-line power are formulated as interpreted in equation (1).

$$
A C E_{i}=B_{i} \Delta f_{1}+\Delta P_{t i e, i j}
$$

where ' $\mathrm{i}$ ' and ' $\mathrm{j}$ ' are the corresponding area and different area, respectively. $\mathrm{B}$ is the bias constant. A small step disturbance of $10 \%(0.1)$ is implemented in area $1\left(\Delta \mathrm{P}_{\mathrm{D} 1}\right)$ to observe the performance of the controllers. 


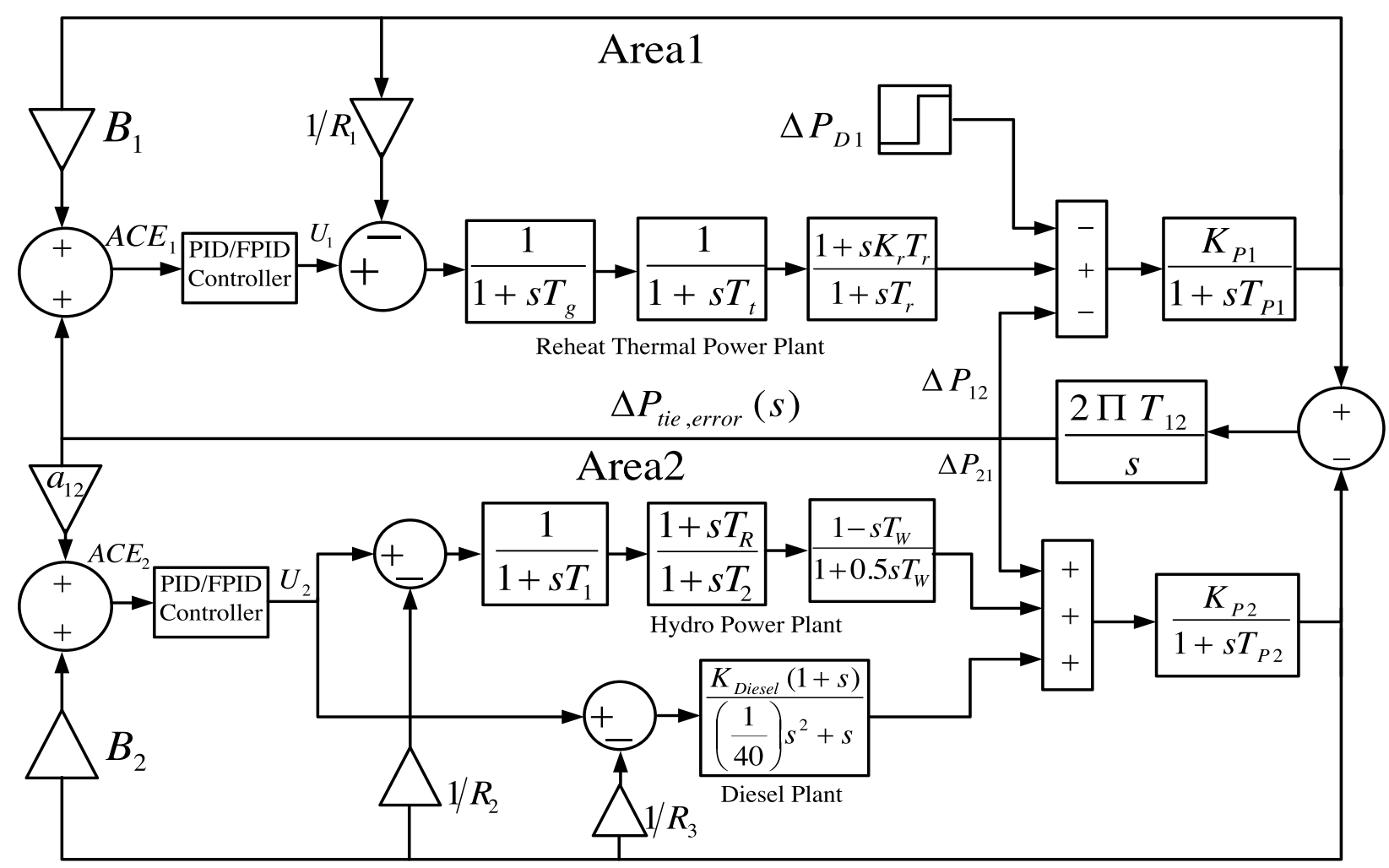

Figure 1. Interconnected hydro-thermal-diesel power system model.

The prime target of controller in this system is to set ACE to zero. For this purpose PID and fuzzy PID (FPID) controllers are imposed in both areas. The inputs to the controller in one area are the ACEs of that respective area and the outputs are $\mathrm{U}_{1}, \mathrm{U}_{2}$, and $\mathrm{U}_{3}$. The objective function adopted for this proposed model is ITAE (Integral Time Absolute Error) by concerning $\Delta \mathrm{f}_{1}, \Delta \mathrm{f}_{2}$, and $\Delta \mathrm{P}_{\text {tie }}$. ITAE is adopted to reduce overshoot, undershoot, and settling time of the system. In ITAE, the severity of the errors gradually increases with respect to time. So ITAE is a better cost function to concern the transient performance of the system. PID and FPID controllers are adopted to lessen the ITAE value of the system.

ITAE is mathematically formulated as portrayed in equation (2).

$$
I T A E=\int_{0}^{t_{s i m}}\left(\left|\Delta f_{1}\right|+\left|\Delta f_{2}\right|+\left|\Delta P_{t i e}\right|\right) \cdot t \cdot d t
$$

To achieve the better ITAE value, it is significant to choose the gain parameters of the controller by adopting convenient optimization techniques.

\section{CONTROLLER STRUCTURE}

The design of controller is also significant to enhance the performance of the system. PID and FPID controllers are employed individually in both the areas. Many researchers have validated the superiority of FPID controller than traditional PID controller. The framework of PID and FPID controllers is portrayed in figure 2 and figure 3, respectively. 
Table 1. Rule structure.

\begin{tabular}{cccccc}
\hline ACE & \multicolumn{5}{c}{$\Delta \mathbf{A C E}$} \\
\hline & HN & LN & M & LP & HP \\
\cline { 2 - 6 } HN & HN & HN & LN & LN & M \\
LN & HN & LN & LN & M & LP \\
M & LN & LN & M & LP & LP \\
LP & LN & M & LP & LP & HP \\
HP & M & LP & LP & HP & HP \\
\hline
\end{tabular}

The Mamdani max-min inference system is adopted as inference engine and center of Gravity (COG) approach is adopted as defuzzification of processed data. The rule structure is characterized in table1. The operation of the FLC is illustrated in figure 5. Fuzzy Logic Controller (FLC) is superior over PID to control non-linear, imprecise and uncertain information. Two trapezoidal membership functions (MFs) and three triangular MFs entitled as Highly Negative (HN), Less Negative (LN), Middle (M), Less Positive (LP), and Highly Positive (HP) are used as illustrated in figure 4.

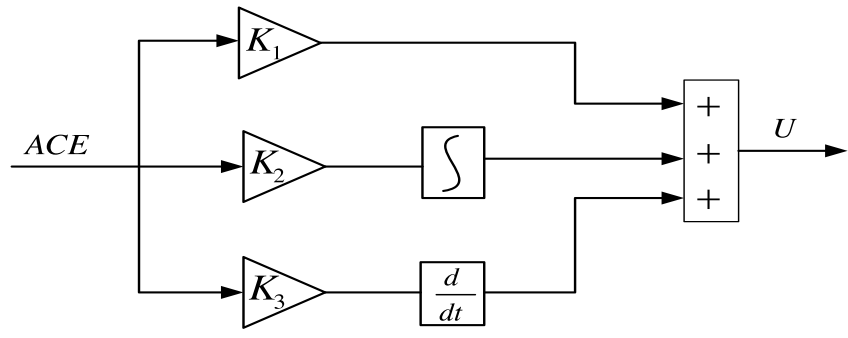

Figure 2. PID controller structure of area 1.

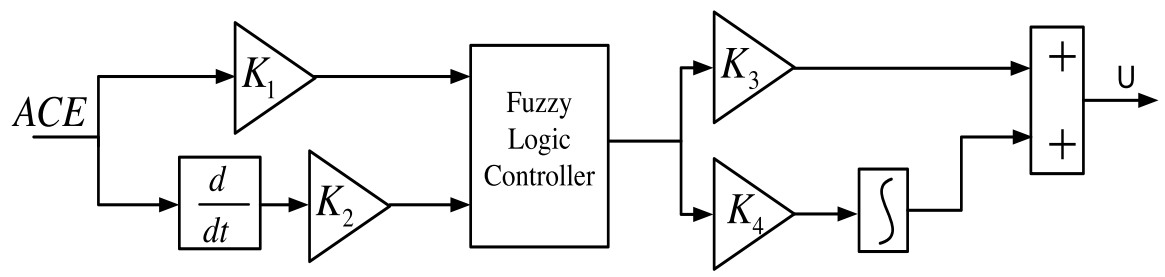

Figure 3. Fuzzy PID controller structure of area 1.

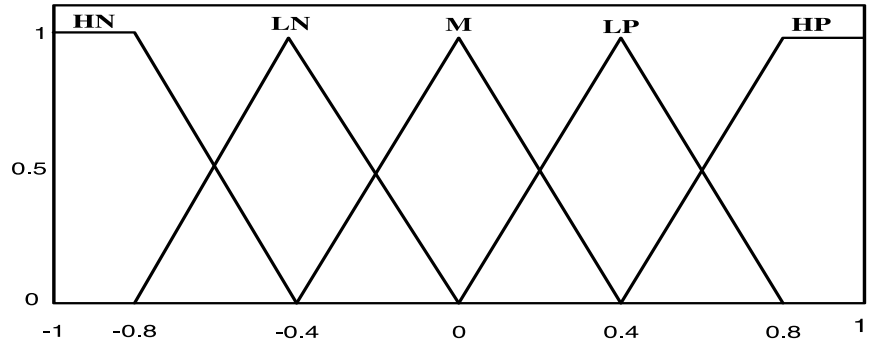

Figure 4. Membership functions of FLC. 


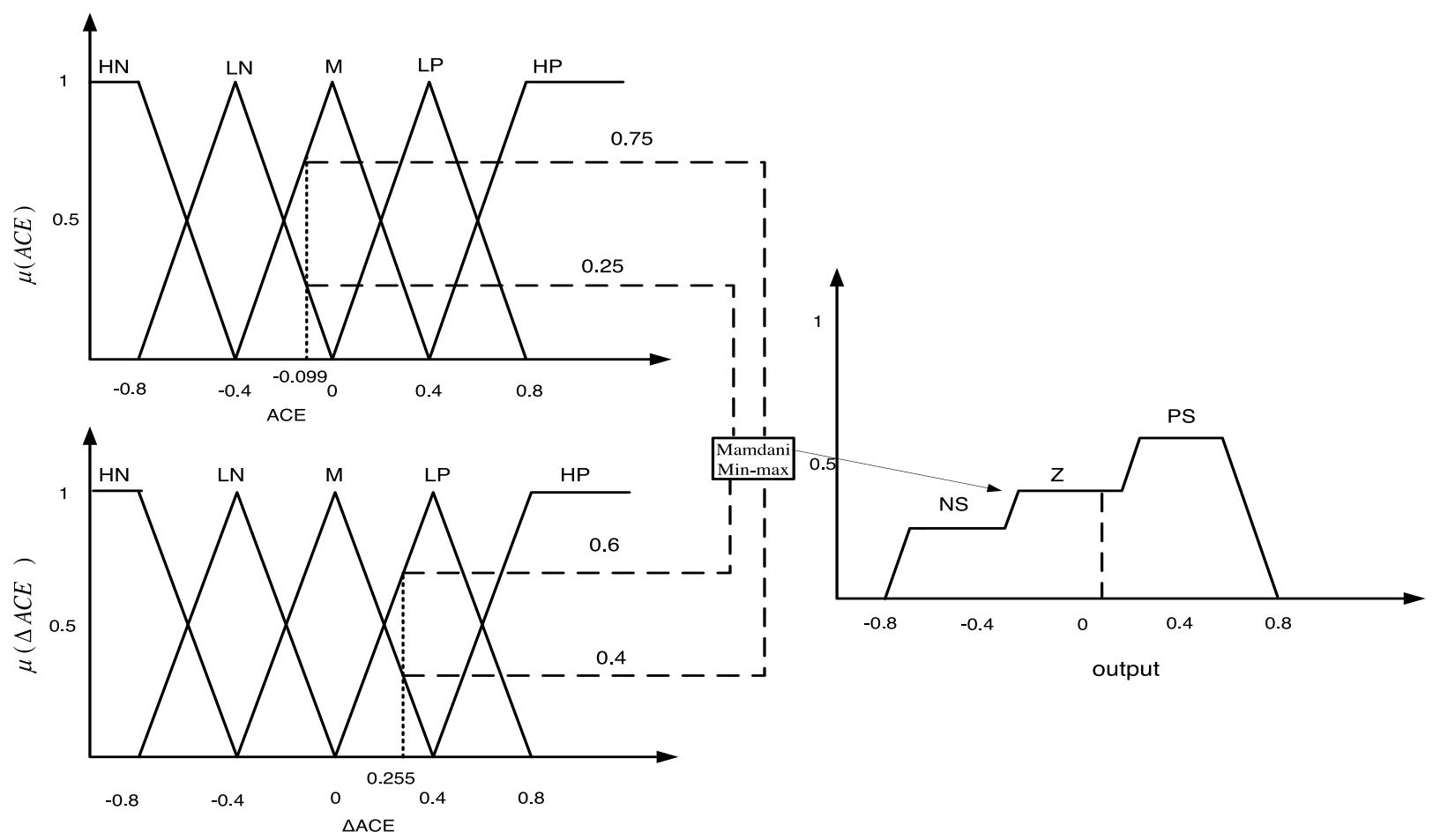

Figure 5. Mamdani min-max operation of FLC.

\section{HYBRID ALOPEX-BASED Differential Evolution Craziness based Particle Swarm Optimization (ADECRPSO)}

A novel hybrid ADECRPSO algorithm is validated with various optimization techniques (DE, ADE, PSO, and CRPSO) to tune the design variables of FPID controller to enhance the performance of proposed system. Differential Evolution (DE) is an evolutionary algorithm illustrated in Storn et al. (1997). DE is established by concerning three significant stages like mutation, crossover, and selection. The population in DE is accelerated with very immense diversity factor. There may be a probability to ambush into local optima due to huge diversity and inadequacy memory of DE. To enhance the performance, mutation of DE algorithm is modified by alopex based strategy as characterized in Tzanakou et al. (1979). This altered mutation strategy assists to discover the probability of direction by correlating fitness of two distinct individuals. This strategy enhances the range of the search space and is defined in Leon (2017).

PSO is a swarm based algorithm proposed by Kennedy et al. (1995). PSO is mostly established by concerning the particle's own best $\left(\mathrm{P}_{\text {Best }}\right)$ and the best among all particles $\left(\mathrm{G}_{\text {Best }}\right)$. The memory of this algorithm to store last best value and the current best value makes this algorithm precise. The bizarre movement of the fish and bird colony is narrated to customize the velocity expression of PSO and is established as craziness based PSO (CRPSO) (Kar et al., 2012; Saha et al., 2013; Upadhyay et al., 2014). The balance between exploration and exploitation is maintained by using the random values and their mirror values to alter the velocity. The preeminent goal of this work is to establish a hybrid algorithm by concerning the advantages of both ADE and CRPSO algorithms. The worst particles in each iteration are replaced by randomly generated particles to yield higher probability to get optimal solution. The parameters of the algorithm are illustrated in appendix-2 and the flow chart of ADECRPSO is portrayed in figure 6. 
The steps pursued by this hybrid ADECRPSO algorithm are as follows:

1. Initialize the population i.e. $[\mathrm{X}]_{\mathrm{NP} \times \mathrm{D}}$.

2. Initialize the velocity of the particles of the population for PSO i.e. $[\mathrm{V}]_{\mathrm{NP} \times \mathrm{D}}$.

3. Set $\mathrm{F}, \mathrm{CR}, \mathrm{V}_{\text {craziness }}, \mathrm{C}_{1}, \mathrm{C}_{2}$.

4. Set $\mathrm{T}=1$.

5. Alopex based DE operation

i. Mutation

Correlation (C) between two random individuals $A=\left(a_{1}, a_{2}, \ldots, a_{D}\right)$ and $B=\left(b_{1}, b_{2}, \ldots, b_{D}\right)$ is calculated as characterized in equation (3).

$C_{i, j}=\left(a_{j}-b_{j}\right)[f(A)-f(B)]$

where $i=1,2, \ldots, N P$ and $j=1,2, \ldots, D . f(A)$ and $f(B)$ are the functional values of individuals $A$ and $B$, respectively.

Temperature $(\mathrm{T})$ is the mean value of correlation vectors of last generation and is characterized in equation (4).

$T=\frac{1}{D} \frac{1}{N P} \sum_{i=1}^{N P} \sum_{j=1}^{D}\left|C_{i, j}\right|$

The probability of negative direction may be characterized as in equation (5).

$$
P_{j}=\frac{1}{1+e^{\frac{C_{j}}{T}}}
$$

The movement direction is described mathematically in equation (6).

$$
\delta_{j}= \begin{cases}1 & \text { If } P_{j} \geq \text { rand } \\ -1 & \text { Otherwise }\end{cases}
$$

The mutation is estimated by using equation (7).

$V_{i, j}=a_{j}+\delta_{j} \cdot\left|a_{j}-b_{j}\right| . F$

ii. Crossover

Offspring vector $(\mathrm{V})$ is characterized by concerning crossover rate (CR) in equation (8).

$U_{i, j}= \begin{cases}V_{i, j} & \text { If rand } \leq C R \\ X_{i, j} & \text { Otherwise }\end{cases}$

iii. Selection

The particles with better fitness value are selected as target vector as characterized in equation (9).

$$
X_{i, j}= \begin{cases}U_{i, j} & \text { If } f\left(U_{i, j}\right) \leq f\left(X_{i, j}\right) \\ X_{i, j} & \text { If } f\left(X_{i, j}\right) \leq f\left(U_{i, j}\right)\end{cases}
$$


6. Craziness based PSO

i. Identify the individual best $\left(\mathrm{P}_{\text {best }}\right)$ and best among individual best $\left(\mathrm{G}_{\text {best }}\right)$.

ii. Velocity of the particle is defined in equation (10).

$V_{i}^{k+1}=r_{2} \times S_{r_{3}} \times V_{i}^{k}+\left(1-r_{2}\right) \times c_{1} \times r_{1}\left(P_{\text {best }}-X_{i}\right)+\left(1-r_{2}\right) \times c_{2} \times$

$\left(1-r_{1}\right)\left(G_{\text {best }}-X_{i}\right)$

Where, $S_{r_{3}}= \begin{cases}-1 & \text { If } r_{3} \geq 0.05 \\ 1 & \text { otherwise }\end{cases}$

Velocity is modified by conceding craziness factor as in equation (11).

$V_{i}^{k+1}=V_{i}^{k+1}+P_{r_{4}} \times S_{r_{4}} \times V_{\text {craziness }}$

Where $P_{r_{4}}=\left\{\begin{array}{lr}1 & \text { If } r_{4} \geq P_{r} \\ 0 & \text { Otherwise }\end{array}\right.$

and $S_{r_{4}}= \begin{cases}-1 & \text { If } r_{4} \geq 0.5 \\ 0 & \text { Otherwise }\end{cases}$

$\mathrm{r}_{1}, \mathrm{r}_{2}, \mathrm{r}_{3}$ and $\mathrm{r}_{4}$ are the random numbers [0 1 1].

The particle position is altered as in equation (12).

$X_{i, \text { new }}=X_{i}+V_{i}$

The particle position is updated by concerning fitness values as in equation (13).

$X_{i, j}= \begin{cases}X_{i, \text { new }} & \text { If } f\left(X_{i, \text { new }}\right) \leq f\left(X_{i}\right) \\ X_{i} & \text { Otherwise }\end{cases}$

7. The worst particles are replaced by the random particles to enhance the probability to extract optimum point. The numbers of worst particles are decided by using equation (14) and replaced by new particles as described in equation (15). 


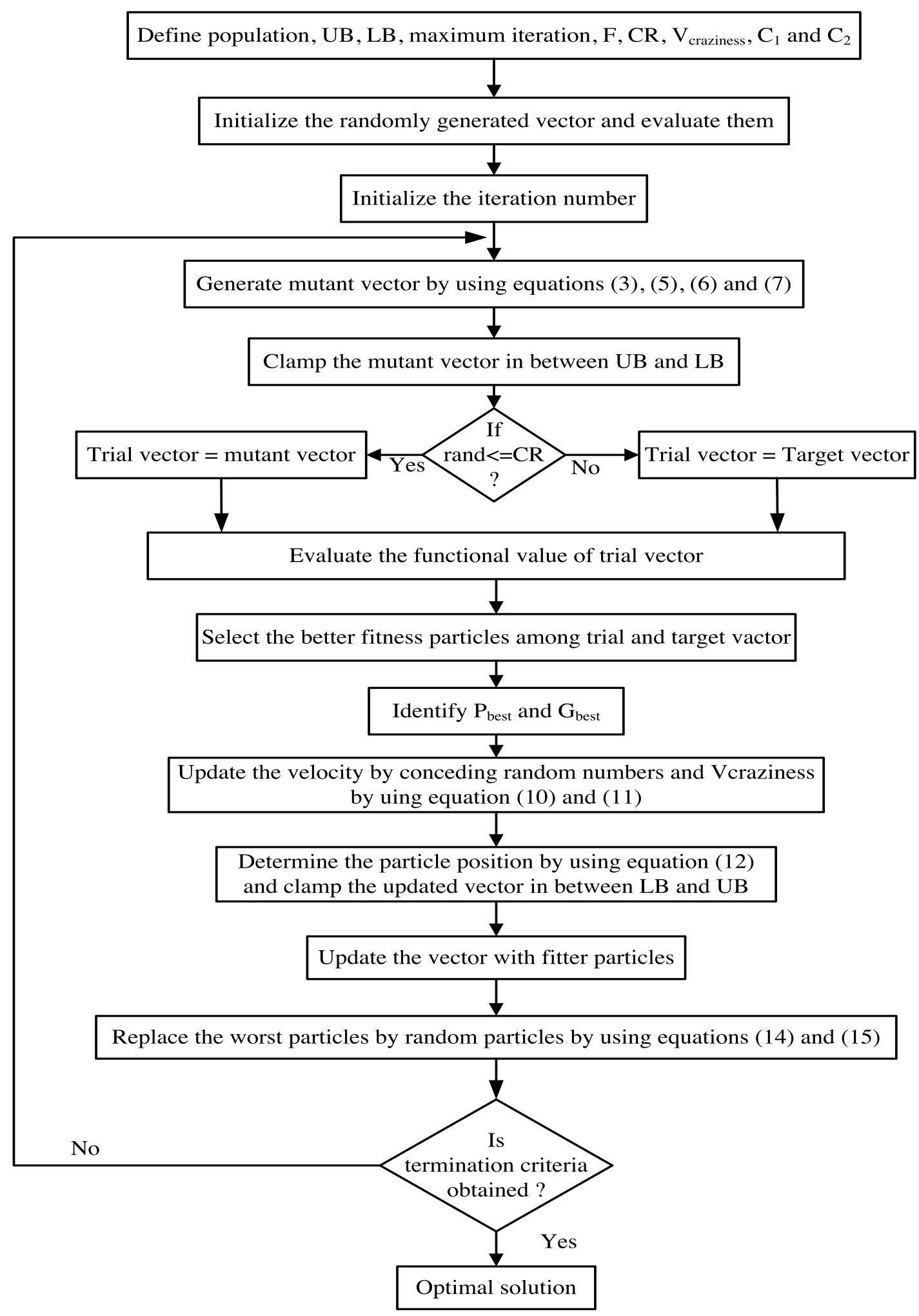

Figure 6. Flow chart of hybrid ADECRPSO algorithm. 


$$
\begin{aligned}
& N=\operatorname{find}\left(\left(f\left(G_{\text {Best }}\right)+M\right)<f\left(X_{i}\right)\right) \\
& X_{i}(N)=\min \left(X_{i}\right)+\operatorname{rand} \times\left(\max \left(X_{i}\right)-\min \left(X_{i}\right)\right)
\end{aligned}
$$

where $\mathrm{N}$ and $\mathrm{M}$ are the number of particles to be replaced and the threshold value beyond which particles are to be replaced, respectively.

8. The iteration is updated by one and repeats the steps 5 and 7 until maximum iteration.

\section{RESULT AND DISCUSSION \\ Transient performance analysis}

This paper is proposed to validate the proficiency of the novel hybrid Alopex based Differential Evolution Craziness based Particle Swarm Optimization (ADECRPSO) to tune the scaling factors of PID and FPID controller. PSO, DE, CRPSO, and ADE are adopted to investigate the performance of hybrid ADECRPSO algorithm. All the algorithms are executed individually to optimize the parameters of controller with number of population 50 and maximum iteration as 100. PID controller is optimized by only ADECRPSO algorithm to portray the proficiency of FPID controller. The fundamental goal of AGC is to lessen the objective function (ITAE) or to set the ACE to zero.

To interpret the activity of the AGC a load disturbance of $10 \%(0.1)$ is applied in area 1 . The gain parameters of conventional PID controller optimized by ADECRPSO algorithm are as $\mathrm{K}_{1}=1.9175, \mathrm{~K}_{2}=1.5822, \mathrm{~K}_{3}=0.9092$ in area 1 and $\mathrm{K}_{1}=0.6735, \mathrm{~K}_{2}=0.1276, \mathrm{~K}_{3}=1.4844$ in area-2, respectively. The gain factors of FPID controller tuned by assorted algorithms are illustrated in table 2 . The proposed objective function is a multi-variable with boundary constraint as

$$
0.01 \leq K_{i} \leq 2 \quad \mathrm{i}=1,2, \ldots, \mathrm{D}
$$

where $\mathrm{D}$ is the number of gain parameters of the controllers.

Table 2. Optimal gain parameters of FPID controller optimized by different Optimization techniques.

\begin{tabular}{ccccc|cccc}
\hline $\begin{array}{c}\text { Optimization } \\
\text { Techniques }\end{array}$ & \multicolumn{8}{c}{ Gain parameters of FPID controllers } \\
\hline & \multicolumn{3}{c}{ Area-1 } & \multicolumn{5}{c}{ Area-2 } \\
\cline { 2 - 9 } & $\mathbf{K}_{\mathbf{1}}$ & $\mathbf{K}_{\mathbf{2}}$ & $\mathbf{K}_{\mathbf{3}}$ & $\mathbf{K}_{\mathbf{4}}$ & $\mathbf{K}_{\mathbf{1}}$ & $\mathbf{K}_{\mathbf{2}}$ & $\mathbf{K}_{\mathbf{3}}$ & $\mathbf{K}_{\mathbf{4}}$ \\
\cline { 2 - 10 } ADECRPSO & 2.0000 & 1.1063 & 1.9892 & 2.0000 & 1.3646 & 1.4525 & 1.9999 & 2.0000 \\
ADE & 2.0000 & 1.2016 & 1.5036 & 1.9998 & 2.0000 & 0.7802 & 1.3877 & 1.1114 \\
CRPSO & 2.0000 & 2.0000 & 0.7568 & 2.0000 & 0.0100 & 1.5243 & 0.0100 & 1.6908 \\
DE & 2.0000 & 0.8489 & 1.5728 & 2.0000 & 1.6070 & 1.1775 & 0.7770 & 1.4380 \\
PSO & 2.0000 & 0.8831 & 1.3569 & 2.0000 & 0.7676 & 1.0293 & 1.6599 & 0.3983 \\
\hline
\end{tabular}




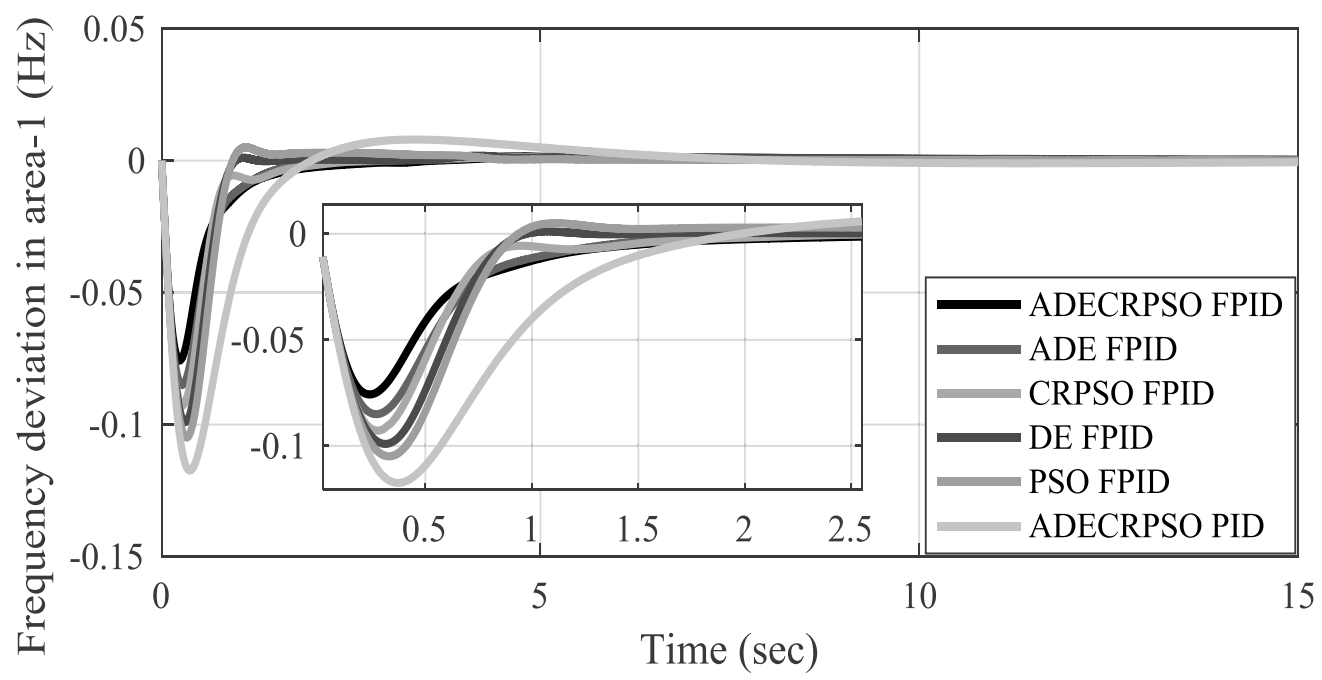

Figure 7. Frequency deviation in area1 (Hz).

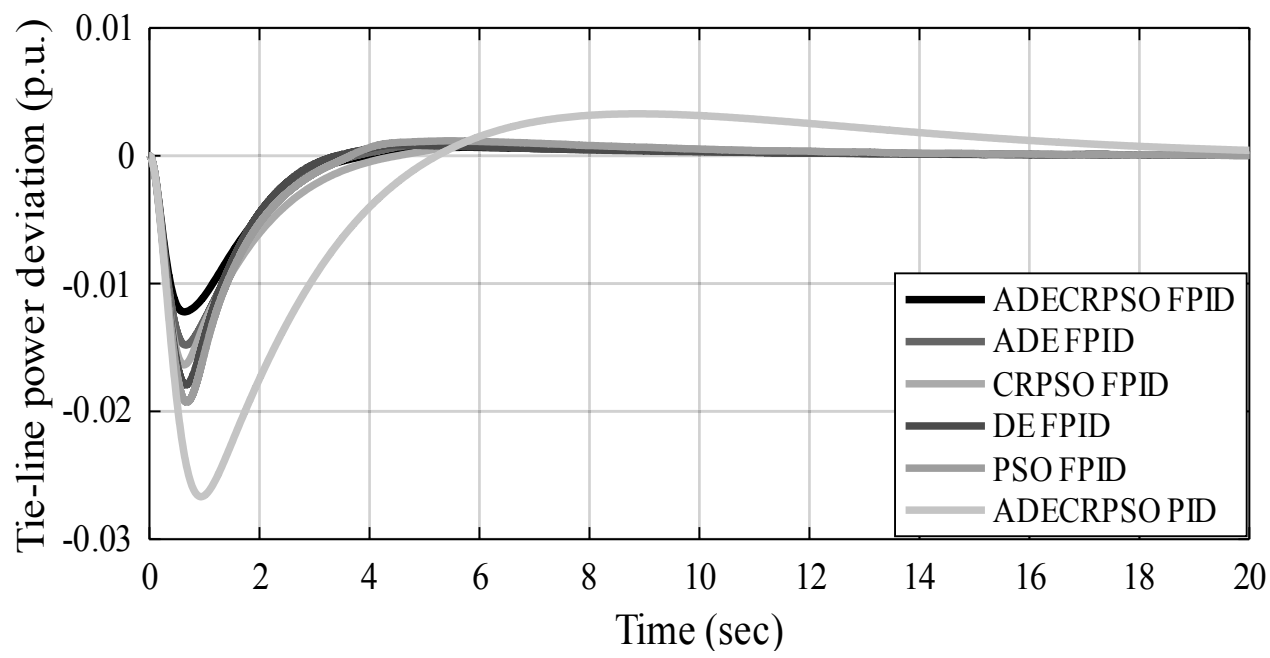

Figure 8. Frequency deviation in area2 (Hz).

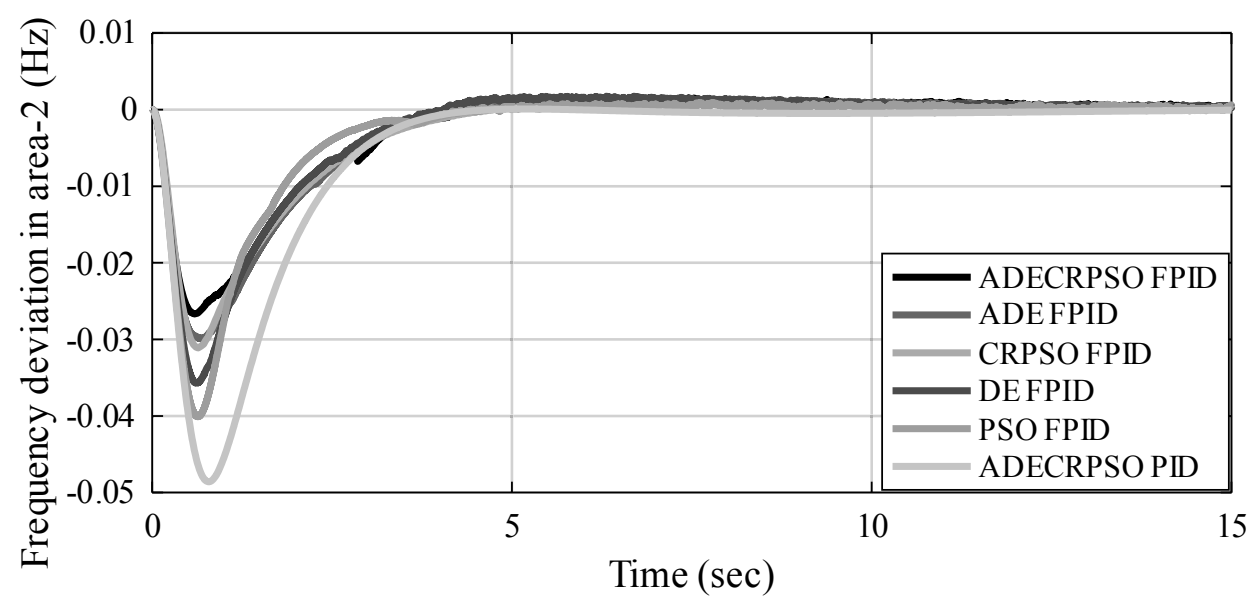

Figure 9. Tie-line power deviation in p.u. 


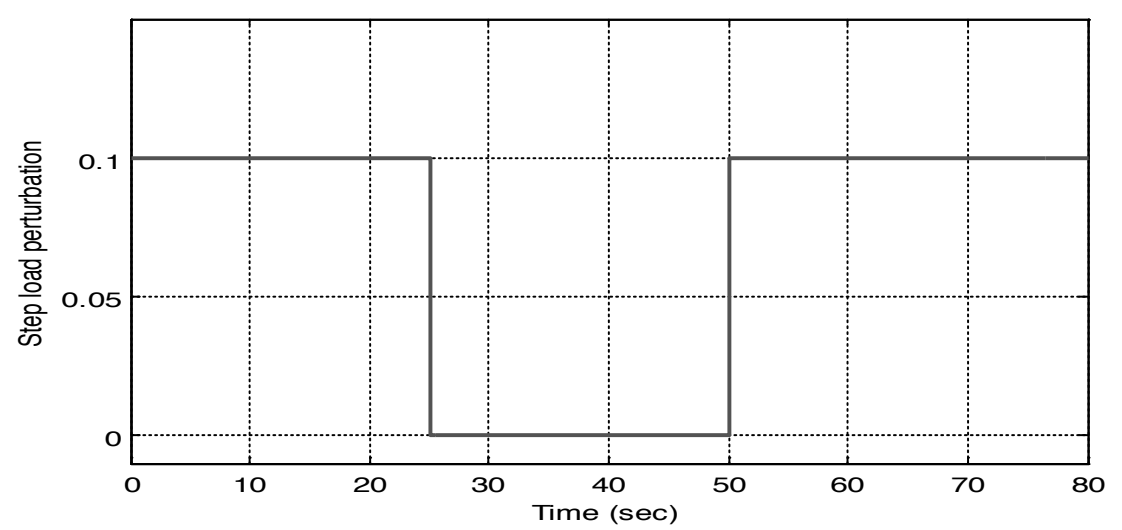

Figure 10. Variable SLP.

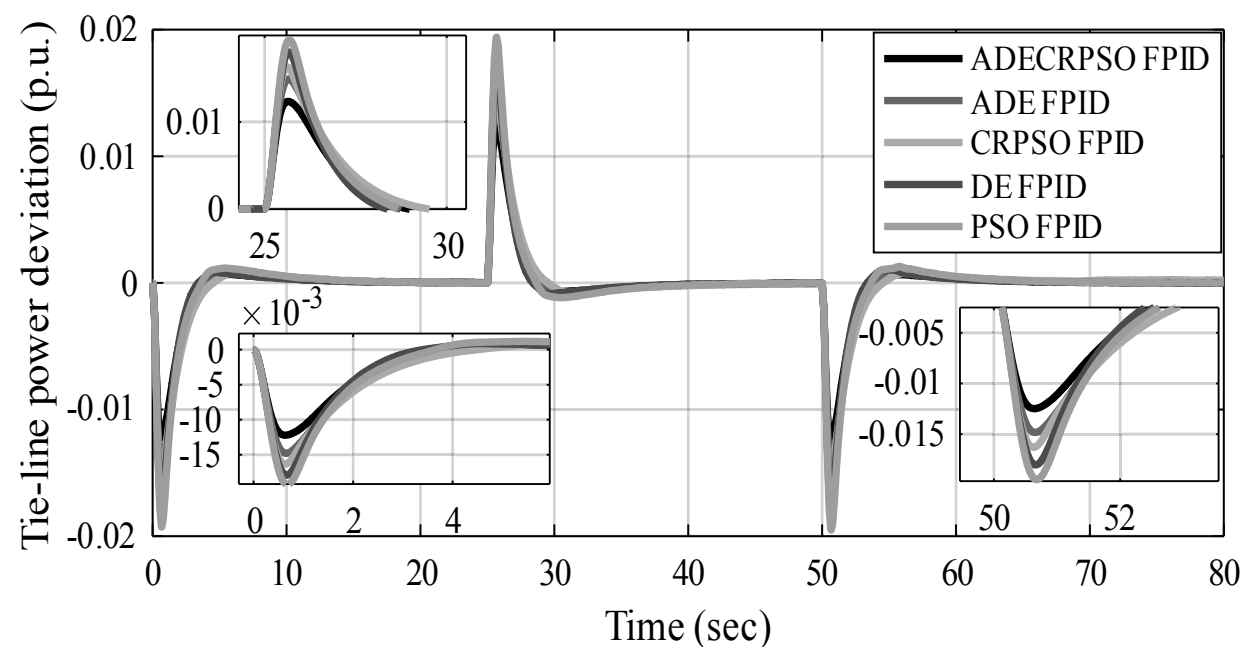

Figure 11. Tie-line power deviation in p.u. with variable SLP.

The deviations of frequency of both area $1 \&$ area $2\left(\Delta \mathrm{f}_{1}\right.$ and $\left.\Delta \mathrm{f}_{2}\right)$ and tie-line power deviation $\left(\Delta \mathrm{P}_{\text {tie }}\right)$ are illustrated in figure 7 , figure 8 , and figure 9 . These figures provide a clear portrait that the response of hybrid ADECRPSO optimized FPID controller is better among all optimization techniques used in this paper. Table 3 encloses the substantial values of undershoot $\left(\mathrm{U}_{\mathrm{sh}}\right)$, overshoot $\left(\mathrm{O}_{\mathrm{sh}}\right)$, and settling time $\left(\mathrm{T}_{\mathrm{s}}\right)$ of the responses.

Table 3. Response parameters of $\Delta \mathrm{f}_{1}, \Delta \mathrm{f}_{2}$, and $\Delta \mathrm{P}_{\text {tie }}$ in the power system controlled by PID and FPID controller.

\begin{tabular}{|c|c|c|c|c|c|c|c|c|c|}
\hline \multirow[t]{2}{*}{$\begin{array}{c}\text { Optimization } \\
\text { Techniques }\end{array}$} & \multicolumn{3}{|c|}{ Undershoot $\left(\mathrm{U}_{\mathrm{sh}} \times 10^{-3}\right)$ in p.u. } & \multicolumn{3}{|c|}{ Overshoot $\left(\mathrm{O}_{\text {sh }} \times 10^{-3}\right)$ in p.u. } & \multicolumn{3}{|c|}{ Settling Time $\left(T_{s}\right)$ in sec } \\
\hline & $\Delta \mathbf{f}_{1}$ & $\Delta \mathbf{f}_{2}$ & $\Delta \mathbf{P}_{\text {tie }}$ & $\Delta \mathbf{f}_{1}$ & $\Delta \mathbf{f}_{2}$ & $\Delta \mathbf{P}_{\text {tie }}$ & $\Delta \mathbf{f}_{1}$ & $\Delta \mathbf{f}_{2}$ & $\Delta \mathbf{P}_{\text {tie }}$ \\
\hline ADECRPSO FPID & -75.7543 & -26.6676 & -12.2101 & 1.6788 & 1.5736 & 0.6746 & 6.4429 & 12.3945 & 7.7508 \\
\hline ADE FPID & -85.0208 & -30.0053 & -14.8024 & 1.6813 & 1.5916 & 0.8519 & 4.2794 & 15.0504 & 7.7925 \\
\hline CRPSO FPID & -92.7974 & -31.1076 & -16.3718 & 1.7852 & 1.6041 & 0.8558 & 8.4861 & 15.7416 & 8.2815 \\
\hline DE FPID & -99.0610 & -35.6975 & -17.9245 & 1.8633 & 1.7619 & 0.8688 & 8.5438 & 17.5158 & 9.9979 \\
\hline PSO FPID & -104.9229 & -40.0832 & -19.2711 & 5.0456 & 1.9114 & 1.1812 & 8.8058 & 27.7851 & 10.2678 \\
\hline ADECRPSO PID & -117.4496 & -48.5940 & -26.6729 & 7.9769 & 0.1579 & 3.2888 & 13.335 & 15.9945 & 19.4725 \\
\hline
\end{tabular}


The values $\mathrm{U}_{\mathrm{sh}}, \mathrm{O}_{\mathrm{sh}}$, and $\mathrm{T}_{\mathrm{s}}$ of hybrid ADECRPSO optimized PID controller are tabulated in table 3. The validation of proposed algorithm based FPID controller is realized in real time environment. The setup of OPALRT OP5600 is illustrated in figure 12. The responses of ADECRPSO, ADE, and CRPSO based FPID controller are portrayed in figures 13-15. The response of tie-line power deviation with a variable step load disturbance is as portrayed in figure 11 and the step load is portrayed in figure 10. The variable SLP is illustrated in figure 9. The ITAE value of hybrid ADECRPSO optimized PID controller is 0.8530 and the functional value of FPID controller optimized by various algorithms is tabulated in table 4 . All the tables and figures yield a clear portrayal that hybrid ADECRPSO optimized FPID controller gives better transient response in two-area interconnected power system.

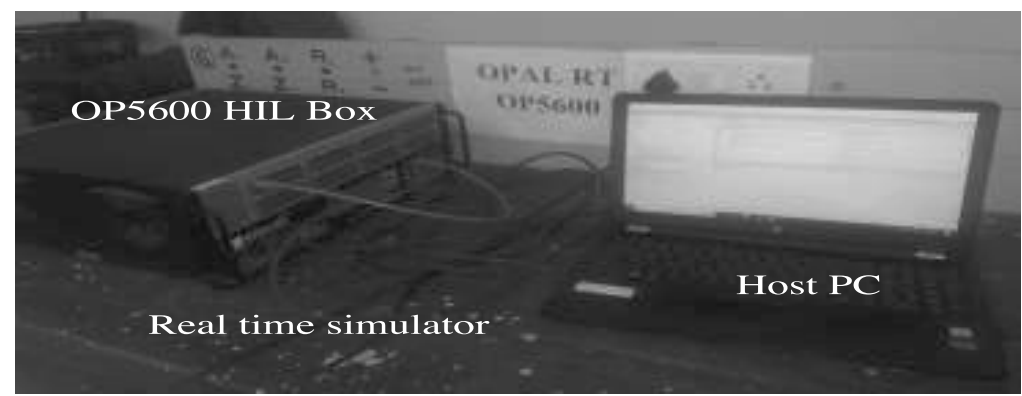

Figure 12. OPAL RT (OP5600) setup.

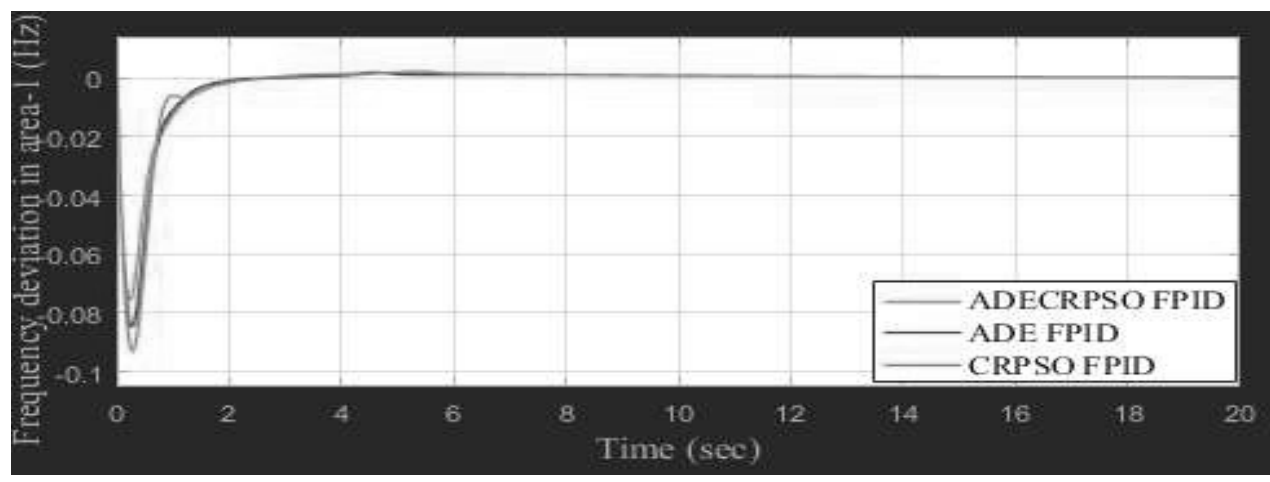

Figure 13. frequency deviation in area-1 in OPAL RT.

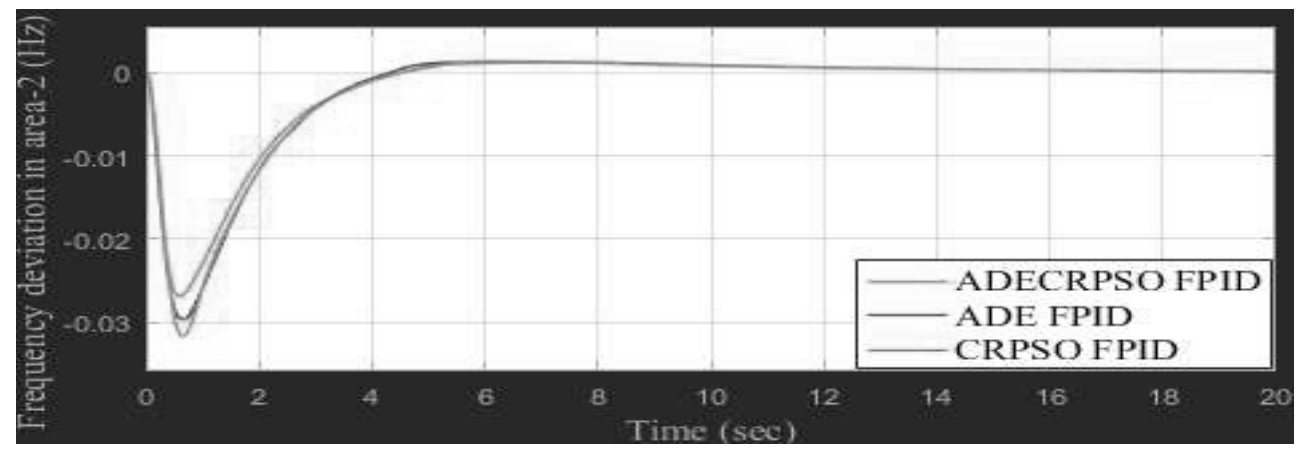

Figure 14. frequency deviation in area-2 in OPAL RT. 


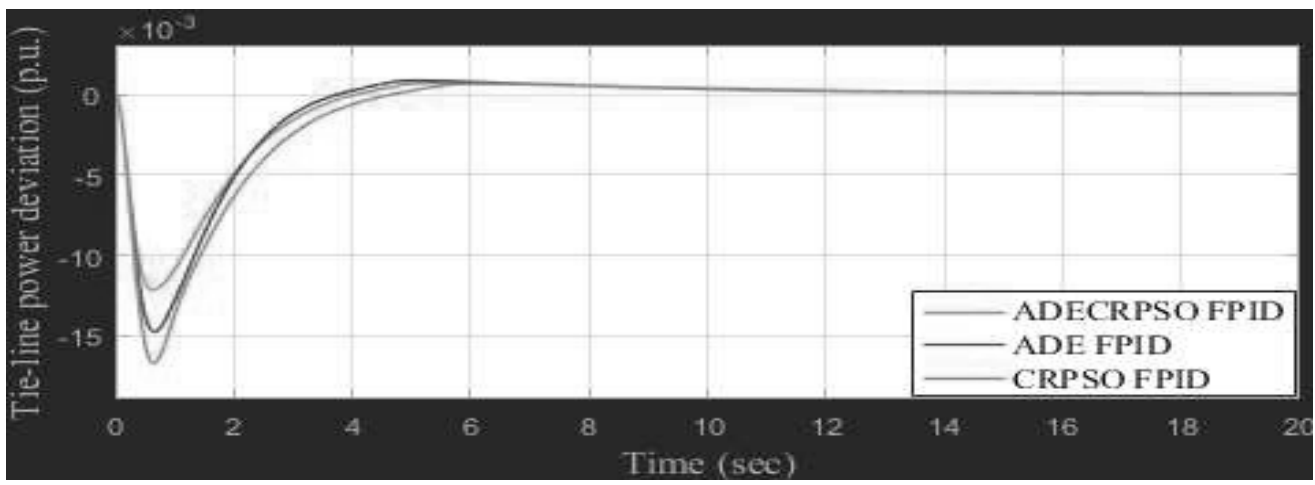

Figure 15. Tie-line power deviation in OPAL RT.

Table 4. Objective functions (ITAE) value for FPID controller optimized by various optimization techniques.

\begin{tabular}{cc}
\hline $\begin{array}{c}\text { Optimization } \\
\text { Techniques }\end{array}$ & $\begin{array}{c}\text { Functional Values } \\
\text { (ITAE) }\end{array}$ \\
\hline ADECRPSO & 0.3162 \\
ADE & 0.3190 \\
CRPSO & 0.3549 \\
DE & 0.3613 \\
PSO & 0.3666 \\
\hline
\end{tabular}

\section{Validation of proposed algorithm}

To cater an equitable contrast between different algorithms tuned PID controller, two-area hydro-thermal power system tuned by hGGSA-PS (Khadanga et al., 2017) and hFA-PS (Sahu et al., 2015b) is adopted. Both areas consists of two equal characteristics hydro and reheat thermal units as portrayed in figure 16 and the system parameters are illustrated in appendix-3. The proposed algorithm is validated by enforcing a small disturbance of $0.015 \mathrm{p} . \mathrm{u}$ and the responses of frequency and tie-line power deviations are portrayed in figure 17, figure 18, and figure 19. The controller variables are tabulated in table 5. The numerical values of response parameters are tabulated in table. 6 . In this section, superiority of alopex based mutation is validated to tune PID controller. Table 7 and figure 17, figure 18, and figure 19 endow an unequivocal interpret about the novelty of alopex based mutation of DE and its hybridization with CRPSO algorithm over DE, PSO, and CRPSO algorithms to yield better performance of the system. 


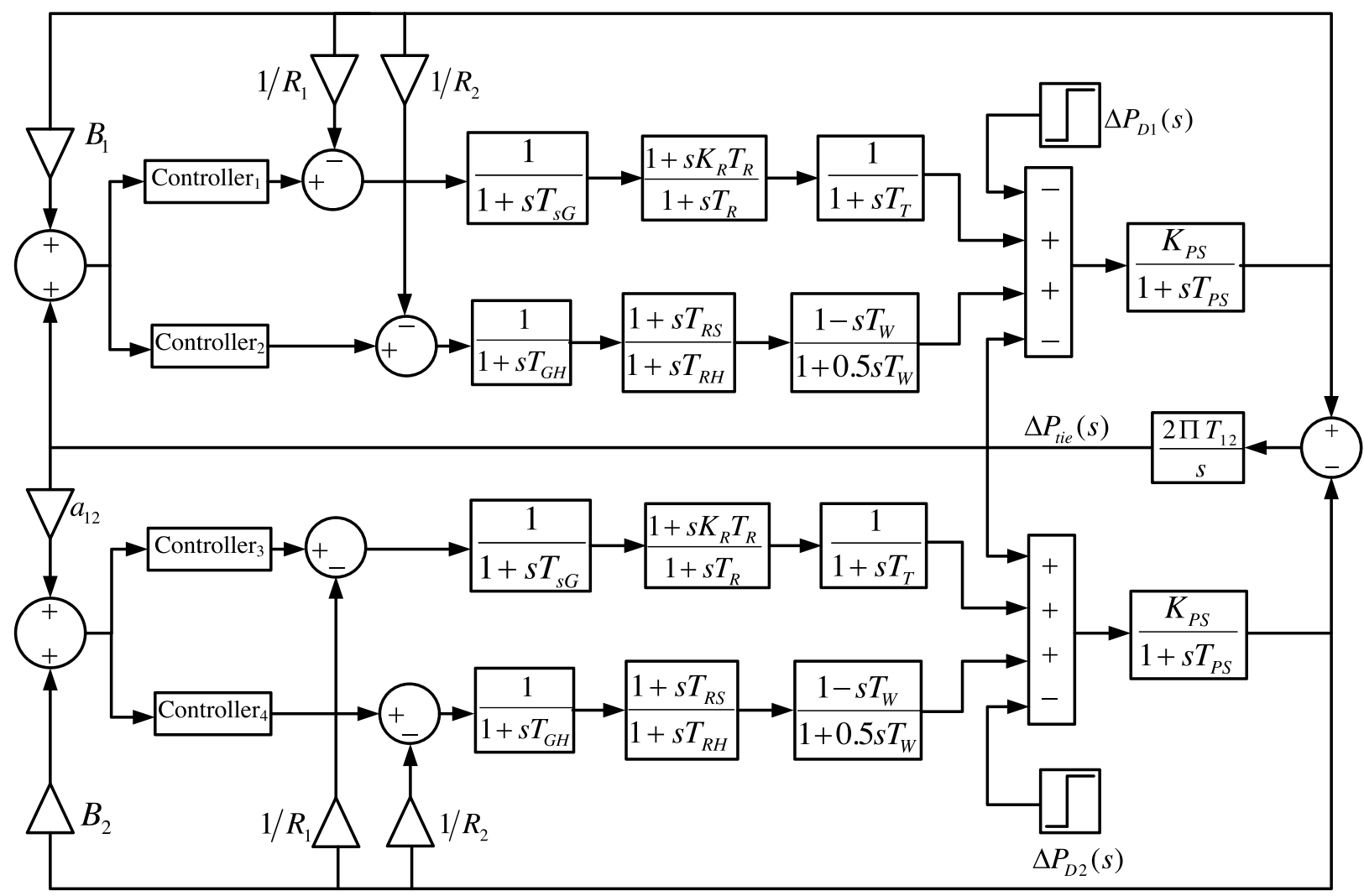

Figure 16. Transfer function model of the two-equal-area hydro-thermal interconnected power system (Khadanga et al., 2017; Sahu et al., 2015b).

Table 5. Optimal parameters of PID and FPID controller tuned by different Optimization techniques.

\begin{tabular}{|c|c|c|c|c|c|c|c|c|c|c|c|c|c|c|c|c|}
\hline \multirow{4}{*}{$\begin{array}{c}\text { Optimization } \\
\text { Techniques }\end{array}$} & \multicolumn{16}{|c|}{ Gain parameters of FPID and PID controllers } \\
\hline & \multicolumn{8}{|c|}{ Area-1 } & \multicolumn{8}{|c|}{ Area-2 } \\
\hline & \multicolumn{4}{|c|}{ Thermal } & \multicolumn{4}{|c|}{ Hydro } & \multicolumn{4}{|c|}{ Thermal } & \multicolumn{4}{|c|}{ Hydro } \\
\hline & $\mathbf{K}_{1}$ & $\mathbf{K}_{2}$ & $\mathbf{K}_{3}$ & $\mathbf{K}_{4}$ & $\mathbf{K}_{1}$ & $\mathbf{K}_{2}$ & $\mathbf{K}_{3}$ & $\mathbf{K}_{4}$ & $\mathbf{K}_{1}$ & $\mathbf{K}_{2}$ & $\mathbf{K}_{3}$ & $\mathbf{K}_{4}$ & $\mathbf{K}_{1}$ & $\mathbf{K}_{2}$ & $\mathbf{K}_{3}$ & $\mathbf{K}_{4}$ \\
\hline ADECRPSO FPID & 2.0000 & 1.4179 & 1.9791 & 1.9989 & 2.0000 & 0.0972 & 1.7644 & 1.6064 & 1.7140 & 1.7325 & 1.7318 & 1.2623 & 1.5548 & 1.9994 & 0.3702 & 1.9315 \\
\hline ADECRPSO PID & 2.0000 & 2.0000 & 1.1135 & & 0.7636 & 0.0100 & 0.9700 & & 1.3254 & 1.1753 & 0.3309 & & 0.0100 & 1.0000 & 1.6236 & \\
\hline ADE PID & 1.9189 & 2.0000 & 1.0128 & & 1.0063 & 0.4793 & 1.8677 & & 1.1871 & 2.0000 & 0.4706 & & 0.2221 & 1.4819 & 0.2393 & \\
\hline CRPSO PID & 1.3113 & 1.9256 & 0.7442 & & 0.8581 & 0.7609 & 0.4874 & & 2.0000 & 0.7900 & 1.2636 & & 0.8147 & 0.6056 & 0.4363 & \\
\hline DE PID & 1.2550 & 1.2348 & 0.6462 & & 0.3846 & 0.4710 & 0.8567 & & 1.0944 & 0.3198 & 0.9124 & & 0.8245 & 0.8263 & 0.6663 & \\
\hline PSO PID & 1.2705 & 1.0037 & 0.5926 & & 0.3983 & 0.6319 & 0.4071 & & 0.8953 & 0.2833 & 0.1577 & & 0.7387 & 0.9399 & 1.4412 & \\
\hline
\end{tabular}


Table 6. Response of $\Delta \mathrm{f}_{1}, \Delta \mathrm{f}_{2}$, and $\Delta \mathrm{P}_{\text {tie }}$ in the power system controlled by PID and FPID controller optimized by various algorithms.

\begin{tabular}{|c|c|c|c|c|c|c|c|c|c|}
\hline Optimization Techniques & Undersh & ot $\left(\mathbf{U}_{\mathrm{sh}} \times \mathbf{1}\right.$ & in p.u. & Oversh & $\left(\mathbf{O}_{\mathrm{sh}} \times\right.$ & in p.u. & Settli & Time & in sec \\
\hline & $\Delta \mathbf{f}_{1}$ & $\Delta \mathbf{f}_{2}$ & $\Delta \mathbf{P}_{\text {tie }}$ & $\Delta \mathbf{f}_{1}$ & $\Delta \mathbf{f}_{2}$ & $\Delta \mathbf{P}_{\text {tie }}$ & $\Delta \mathbf{f}_{1}$ & $\Delta \mathbf{f}_{2}$ & $\Delta \mathbf{P}_{\text {tie }}$ \\
\hline ADECRPSO FPID & -3.2492 & -1.0165 & -0.3943 & $\mathbf{0}$ & $\mathbf{0}$ & $\mathbf{0}$ & 1.32 & 2.21 & 2.14 \\
\hline ADECRPSO PID & -10.3912 & -4.5375 & -1.6993 & 0 & 0 & 0 & 2.65 & 4.24 & 3.54 \\
\hline ADE PID & -11.6964 & -5.1129 & -1.8312 & 0 & 0 & 0 & 2.66 & 4.24 & 3.54 \\
\hline CRPSO PID & -12.7112 & -5.6366 & -2.2490 & 0.4299 & 0 & 0.0426 & 3.71 & 4.96 & 4.45 \\
\hline DE PID & -14.9495 & -6.7548 & -2.7182 & 0 & 0 & 0 & 4.03 & 5.31 & 4.25 \\
\hline PSO PID & -14.9545 & -7.6455 & -2.9389 & 0 & 0 & 0 & 4.97 & 6.13 & 5.10 \\
\hline $\begin{array}{l}\text { hGGSA-PS PID (Khadanga } \\
\text { et al., 2017) }\end{array}$ & -12.7126 & -5.6532 & -2.1601 & 0 & 0 & 0 & 3.15 & 4.52 & 4.02 \\
\hline $\begin{array}{c}\text { hFA-PS PID (Sahu et al., } \\
2015 b)\end{array}$ & -13.8942 & -6.6224 & -2.3886 & 0 & 0 & 0 & 3.42 & 4.98 & 4.15 \\
\hline
\end{tabular}

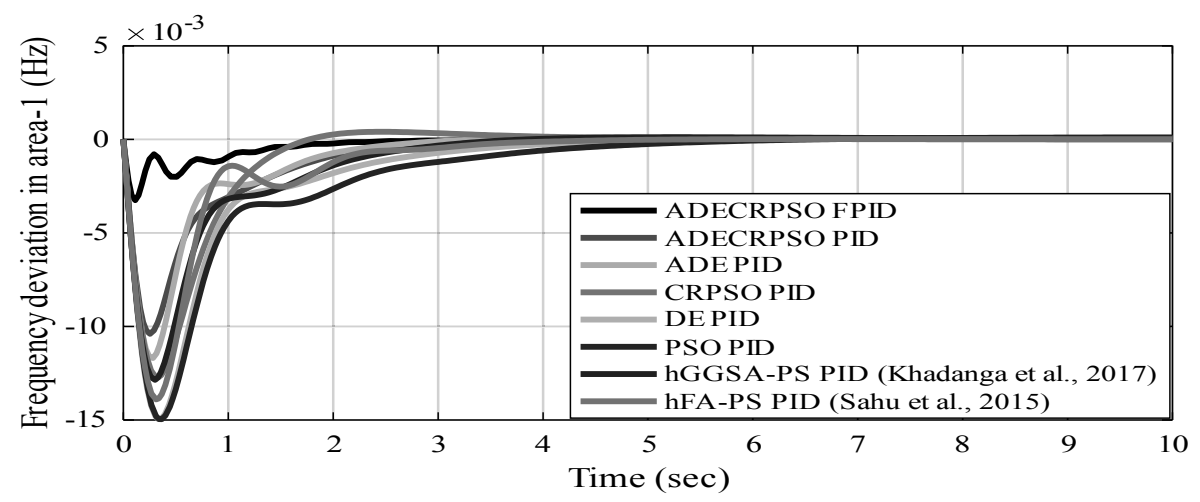

Figure 17. Frequency deviation in area1 $(\mathrm{Hz})$ of two-area hydro-thermal power systems.

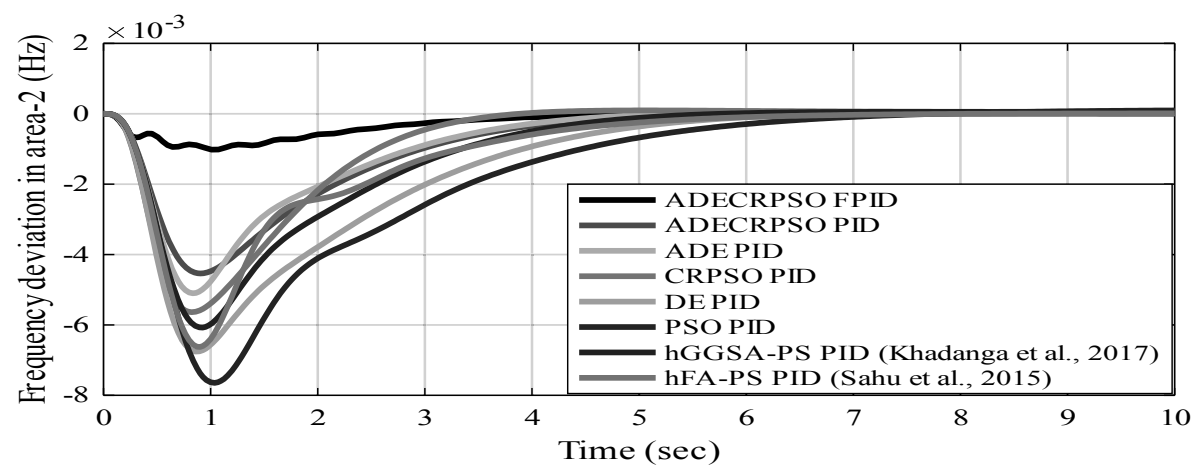

Figure 18. Frequency deviation in area $2(\mathrm{~Hz})$ of two-area hydro-thermal power system. 


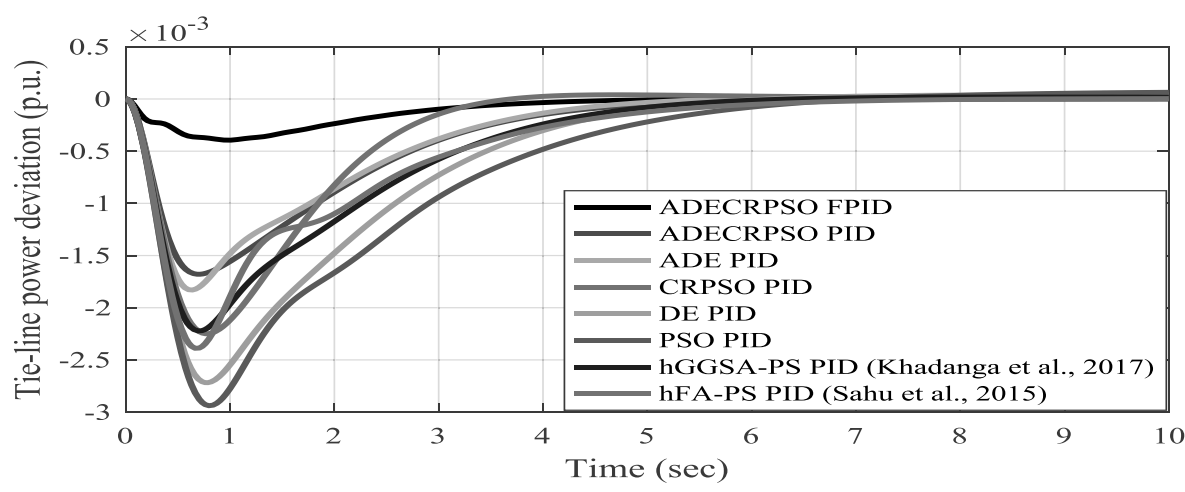

Figure 19. Tie-line power deviation (p.u.) of two-area hydro-thermal power system.

Further, the proposed ADECRPSO optimized FPID controller is substantiated by comparing with ASOS (Nayak et al. 2018c) and BFOA (Arya et al., 2017) optimized FPID controller. The deviations of the system with 1.5\% step load in area-1 are portrayed in figures 20-22.

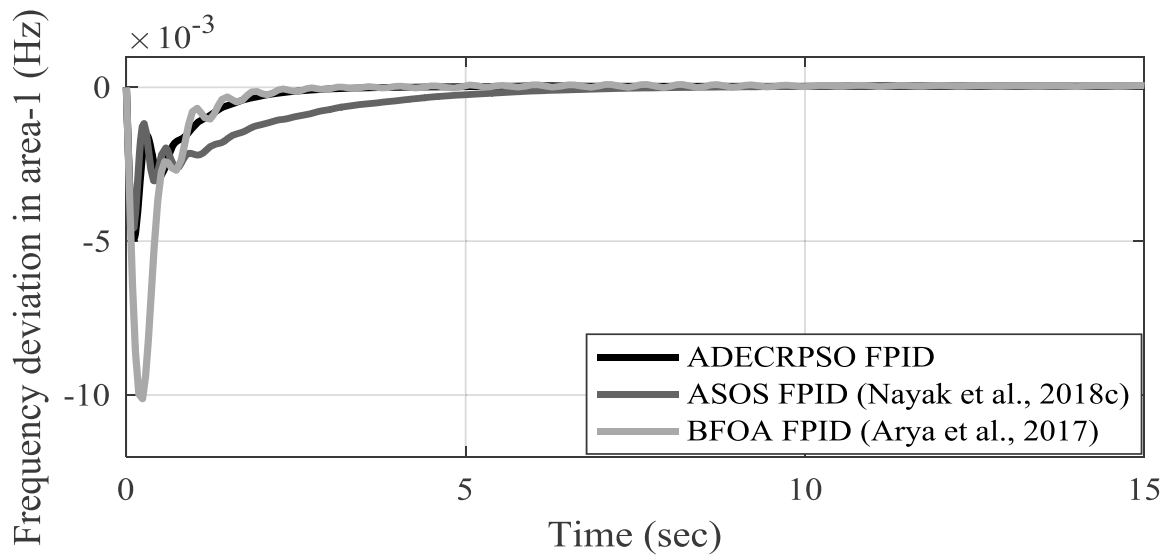

Figure 20. Frequency deviation in area-1 for $1.5 \%$ step load in area-1.

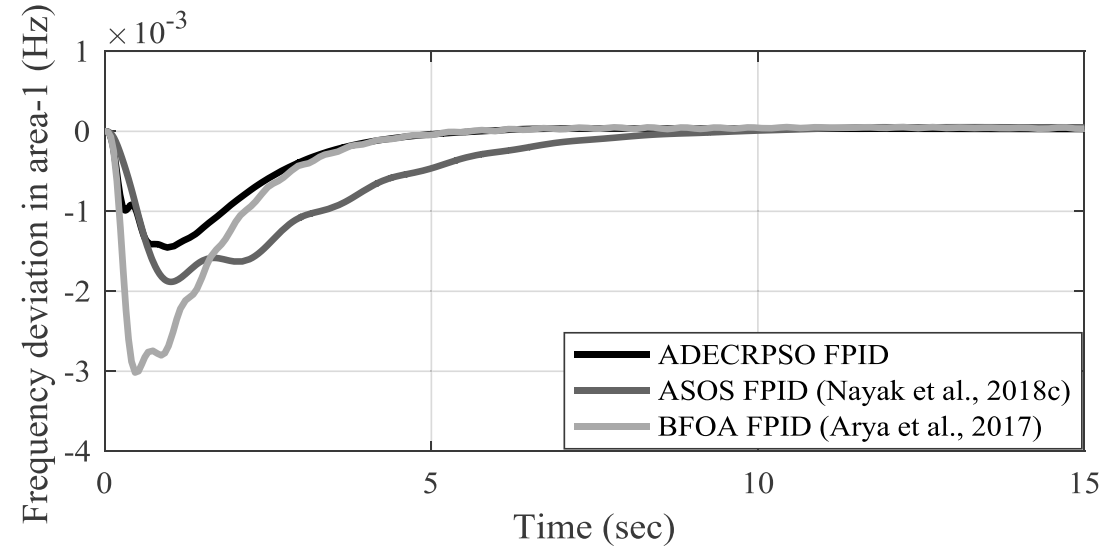

Figure 21. Frequency deviation in area-2 for $1.5 \%$ step load in area-1. 


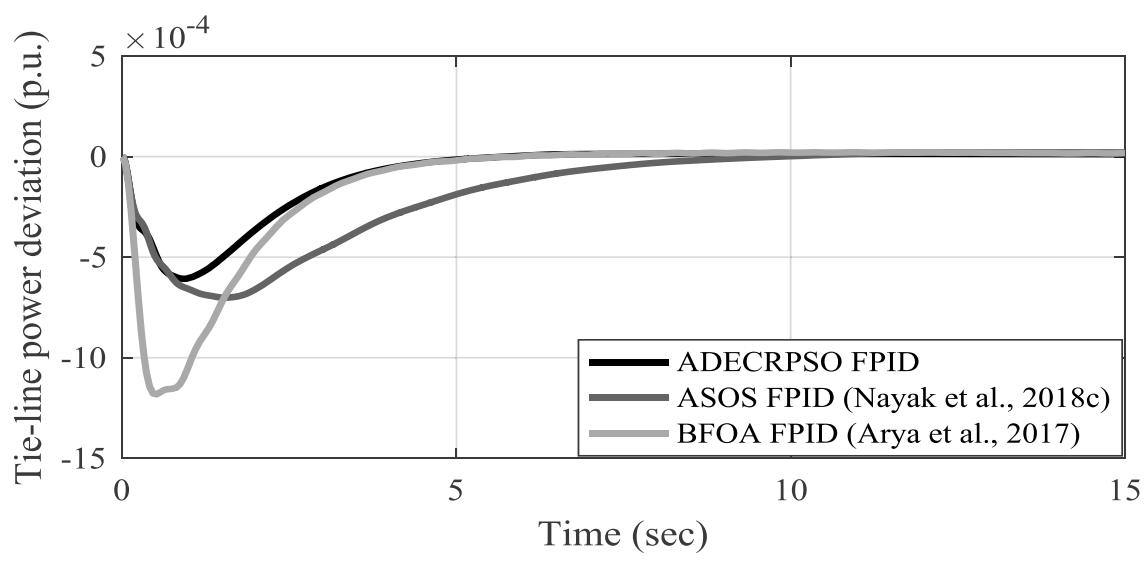

Figure 22. Tie-line power deviation for $1.5 \%$ step load in area-1.

\section{Extension to other power system model}

Further, the validation of acceptability of proposed algorithm is realized by implementing in a three-area thermal-hybrid power system. Thermal power generation unit by conceding physical constraint such as Governor Dead Band (GDB), Reheat turbine, and Boiler Dynamics (BD) is implemented in each area of the power system. Solar Power generation (SPG), Wind Power generation (WPG), Fuel Cell (FC), Aqua Electrolyzer (AE) (Sanki et al. 2018), Diesel Engine (DE), and Battery Energy Storage System (BESS) are implemented as distributed power generation (DPGs) in each area along with reheat thermal power generation unit as depicted in figure 23 (a). The transfer function models of BD and DPGs are illustrated as figure 23 (b) and (c), respectively. The generation capacities of area-1, area-2, and area-3 are in the ratio of 1:3:5, respectively. The power system parameters are indicated in appendix-4. The analysis is realized by implementing $1 \%$ in area of the power system. DE, PSO, CRPSO, ADE, and ADECRPSO are executed individually to tune PID controller parameters to minimize ITAE and the optimal gains of PID controllers are tabulated in table 7. The ADECRPSO tuned parameters of FPID controllers are tabulated in table 7. The system responses are realized by comparing the PID and FPID controllers optimized by different optimization techniques. The system responses of deviations of frequency and tie-line power are portrayed in figure 24-26. 


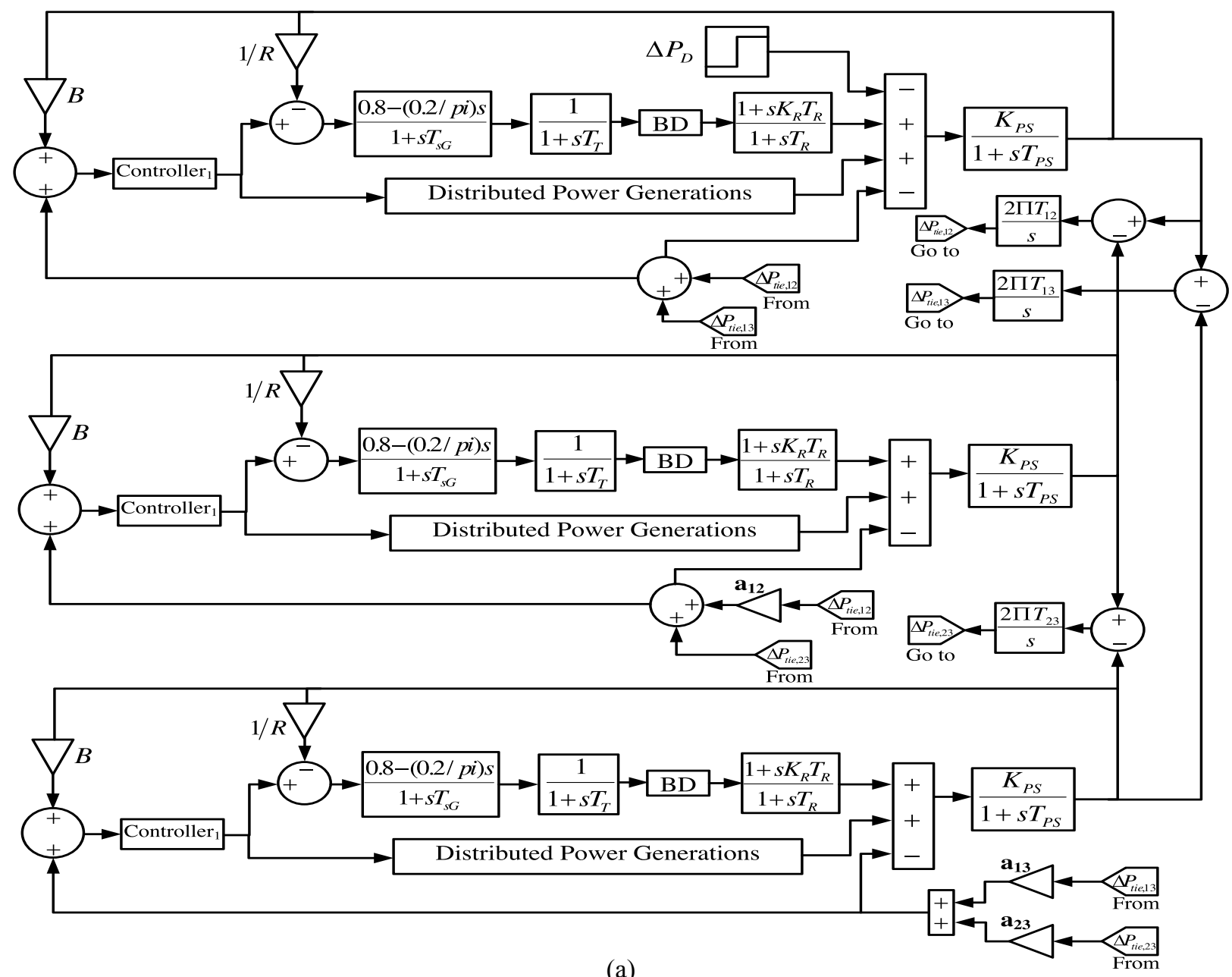

(a)

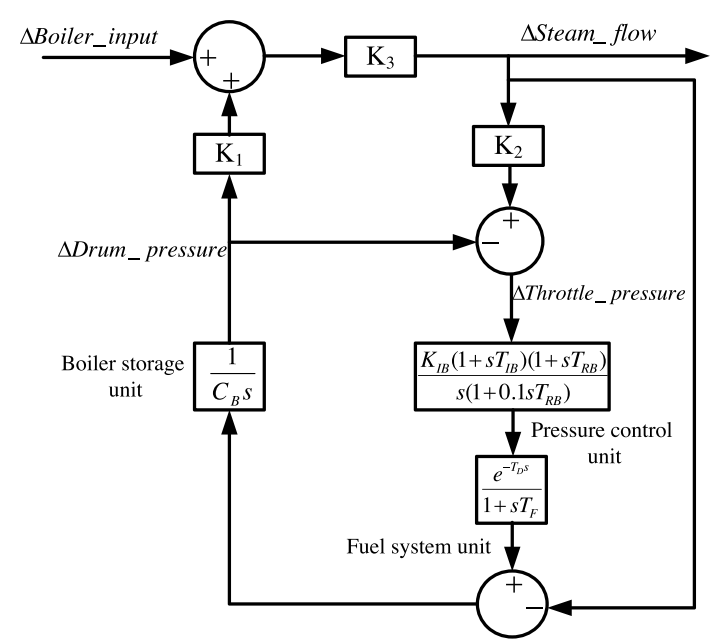

(b)

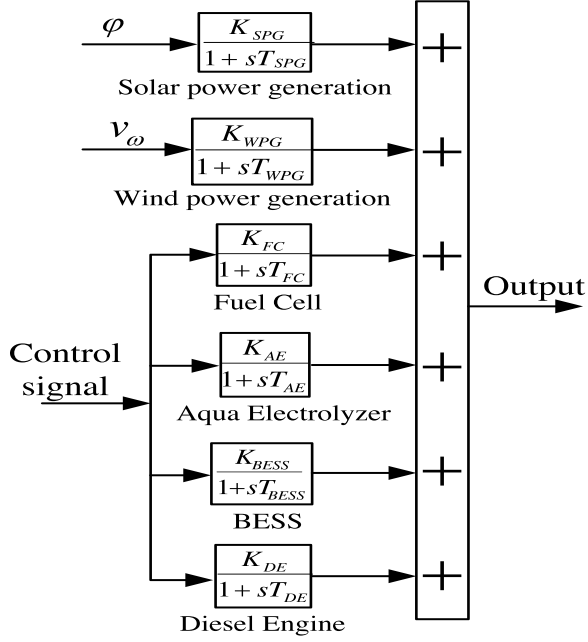

(c)

Figure 23. (a) Three-area thermal-hybrid power system, (b) transfer function model of boiler dynamics, and (c) transfer function modeling of distributed generation unit. 
Table 7. Optimal parameters of PID and FPID controller tuned by different Optimization techniques.

\begin{tabular}{|c|c|c|c|c|c|c|c|c|c|c|c|c|}
\hline \multirow{3}{*}{$\begin{array}{c}\text { Optimization } \\
\text { Techniques }\end{array}$} & \multicolumn{12}{|c|}{ Gain parameters of FPID and PID controllers } \\
\hline & \multicolumn{4}{|c|}{ Area-1 } & \multicolumn{4}{|c|}{ Area-2 } & \multicolumn{4}{|c|}{ Area-3 } \\
\hline & $\mathbf{K}_{1}$ & $\mathbf{K}_{2}$ & $\mathbf{K}_{3}$ & $\mathbf{K}_{4}$ & $\mathbf{K}_{1}$ & $\mathbf{K}_{2}$ & $\mathbf{K}_{3}$ & $\mathbf{K}_{4}$ & $\mathbf{K}_{1}$ & $\mathbf{K}_{2}$ & $\mathbf{K}_{3}$ & $\mathbf{K}_{4}$ \\
\hline ADECRPSO FPID & 1.1929 & 1.0791 & 1.5196 & 1.7456 & 1.3322 & 1.2294 & 1.6431 & 0.9320 & 0.5425 & 0.5584 & 1.6156 & 0.1776 \\
\hline ADECRPSO PID & 0.2035 & 0.7463 & 0.6863 & & 0.3141 & 0.0118 & 1.8690 & & 0.5394 & 0.9556 & 0.9725 & \\
\hline ADE PID & 0.0010 & 0.3532 & 0.8184 & & 0.0690 & 0.4726 & 0.0010 & & 0.8239 & 0.2567 & 1.0667 & \\
\hline CRPSO PID & 0.0100 & 0.2794 & 0.6161 & & 0.0918 & 0.0251 & 1.6277 & & 0.6755 & 0.1132 & 0.1068 & \\
\hline DE PID & 0.1727 & 0.1377 & 0.2128 & & 0.0100 & 0.4156 & 2.0000 & & 0.6115 & 0.6320 & 0.5945 & \\
\hline PSO PID & 0.1201 & 0.0962 & 0.3682 & & 0.1593 & 0.3654 & 1.8875 & & 0.7302 & 0.5895 & 0.3274 & \\
\hline
\end{tabular}

The performances of the system $\left(\mathrm{U}_{\mathrm{sh}}, \mathrm{O}_{\mathrm{sh}}\right.$ and $\left.\mathrm{T}_{\mathrm{s}}\right)$ are graded numerically and are tabulated in table 8 . From table 8 and figures 24-26, ADECRPSO optimized FPID is superior to handle nonlinear power system model. The overall performance of proposed ADECRPSO FPID controller is better over PID controller optimized by different optimization techniques. The objective function (ITAE) is tabulated in table 9.

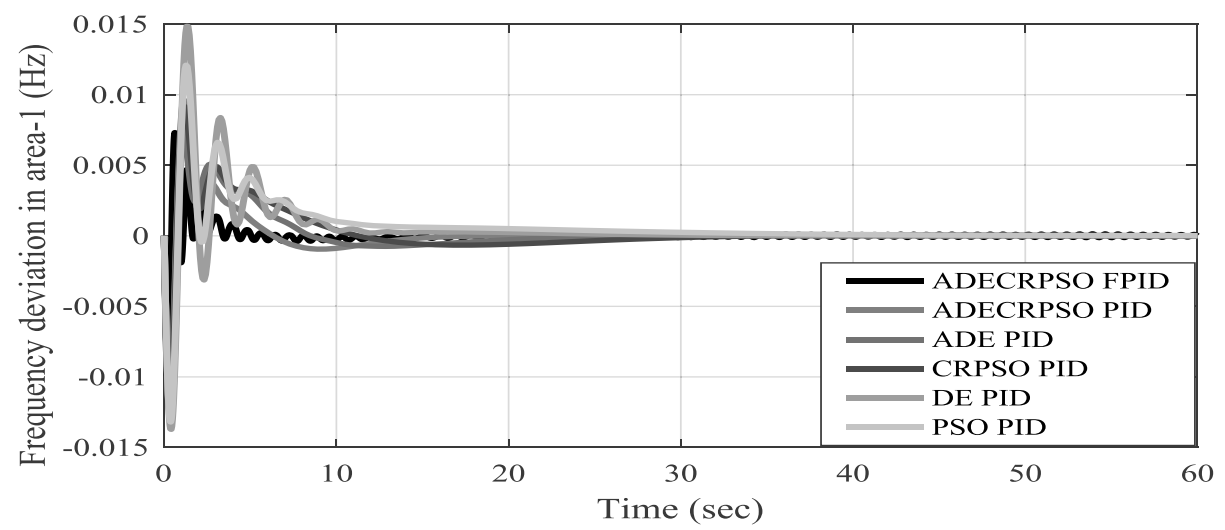

Figure 24. Frequency deviation of areal of three-area thermal-hybrid system.

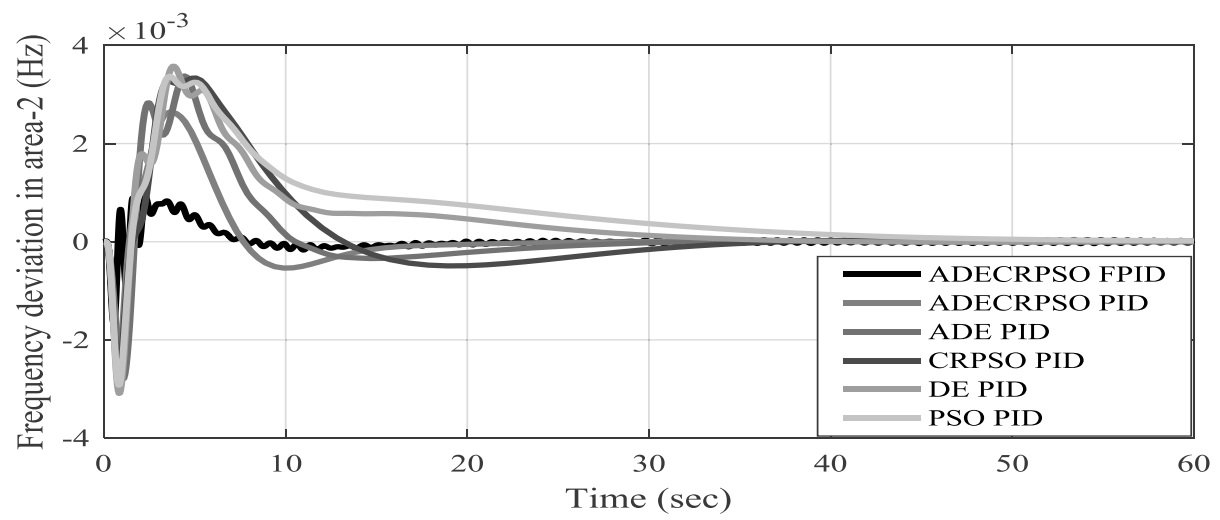

Figure 25. Frequency deviation of area 2 of three-area thermal-hybrid system. 


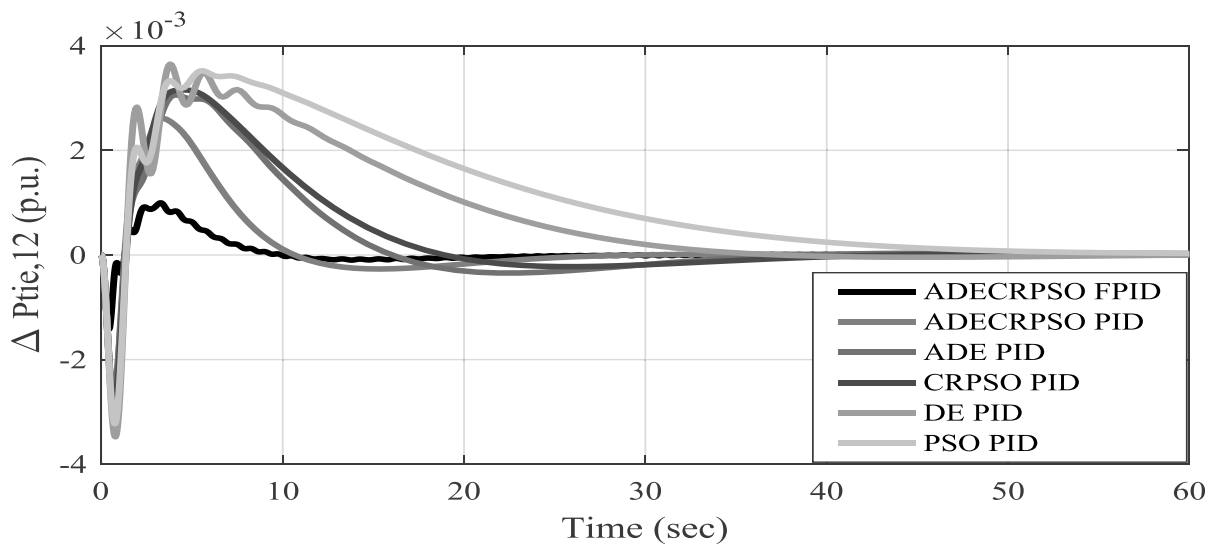

Figure 26. Tie-line power deviation between area 1 and 2 of three-area thermal-hybrid system.

Table 8. Response of the power system controlled by PID and FPID controller optimized by various algorithms.

\begin{tabular}{|c|c|c|c|c|c|c|c|c|}
\hline controllers & $\begin{array}{l}\text { Performance } \\
\text { Parameters }\end{array}$ & $\Delta \mathbf{f}_{1}$ & $\Delta \mathbf{f}_{2}$ & $\Delta \mathbf{f}_{3}$ & $\Delta \mathbf{P}_{\text {tie, } 12}$ & $\Delta \mathbf{P}_{\text {tie }, 13}$ & $\Delta \mathbf{P}_{\mathrm{tie}, 23}$ & ITAE \\
\hline \multirow{3}{*}{ ADECRPSO FPID } & Undershoot $\left(\mathrm{U}_{\mathrm{sh}} \times 10^{-3}\right)$ & -9.9661 & -1.6242 & -0.8531 & -1.4175 & -1.4556 & -0.0090 & \multirow{3}{*}{0.01} \\
\hline & Overshoot $\left(\mathrm{O}_{\mathrm{sh}} \times 10^{-3}\right)$ & 7.2991 & 0.8964 & 0.8067 & 0.9951 & 1.0532 & 0.1457 & \\
\hline & Settling time $\left(\mathrm{T}_{\mathrm{s}}\right)$ & 5.79 & 7.69 & 13.55 & 8.71 & 7.77 & 7.55 & \\
\hline \multirow{3}{*}{ ADECRPSO PID } & Undershoot $\left(\mathrm{U}_{\mathrm{sh}} \times 10^{-3}\right)$ & -12.3124 & -2.5946 & -2.0346 & -2.7381 & -2.8956 & -0.2697 & \multirow{3}{*}{0.9} \\
\hline & Overshoot $\left(\mathrm{O}_{\mathrm{sh}} \times 10^{-3}\right)$ & 9.5963 & 2.6419 & 2.5043 & 2.6090 & 2.7795 & 0.3457 & \\
\hline & Settling time $\left(T_{s}\right)$ & 16.91 & 16.91 & 19.39 & 24.95 & 24.95 & 28.55 & \\
\hline \multirow{3}{*}{ ADE PID } & Undershoot $\left(\mathrm{U}_{\mathrm{sh}} \times 10^{-3}\right)$ & -12.0612 & -2.8012 & -1.7826 & -2.7062 & -2.7751 & -0.4104 & \multirow{3}{*}{2.2} \\
\hline & Overshoot $\left(\mathrm{O}_{\mathrm{sh}} \times 10^{-3}\right)$ & 7.3370 & 3.3552 & 3.0513 & 3.0573 & 3.4062 & 0.5868 & \\
\hline & Settling time $\left(\mathrm{T}_{\mathrm{s}}\right)$ & 24.22 & 27.72 & 26.55 & 34.71 & 35.87 & 30.05 & \\
\hline \multirow{3}{*}{ CRPSO PID } & Undershoot $\left(\mathrm{U}_{\mathrm{sh}} \times 10^{-3}\right)$ & -12.5129 & -2.6741 & -2.4176 & -2.8943 & -3.0785 & -0.3158 & \multirow{3}{*}{2.99} \\
\hline & Overshoot $\left(\mathrm{O}_{\mathrm{sh}} \times 10^{-3}\right)$ & 9.1423 & 3.3356 & 3.3016 & 3.1541 & 3.4743 & 0.4021 & \\
\hline & Settling time $\left(\mathrm{T}_{\mathrm{s}}\right)$ & 30.52 & 33.69 & 33.69 & 37.91 & 38.97 & 38.97 & \\
\hline \multirow{3}{*}{ DE PID } & Undershoot $\left(\mathrm{U}_{\mathrm{sh}} \times 10^{-3}\right)$ & -13.7142 & -3.0849 & -2.7856 & -3.4752 & -3.7222 & -0.3431 & \multirow{3}{*}{5.6} \\
\hline & Overshoot $\left(\mathrm{O}_{\mathrm{sh}} \times 10^{-3}\right)$ & 14.8325 & 3.5752 & 3.4672 & 3.6478 & 3.9736 & 0.4796 & \\
\hline & Settling time $\left(T_{s}\right)$ & 31.85 & 35.62 & 34.59 & 41.77 & 39.73 & 40.74 & \\
\hline \multirow{3}{*}{ PSO PID } & Undershoot $\left(\mathrm{U}_{\mathrm{sh}} \times 10^{-3}\right)$ & -13.1923 & -2.9162 & -2.6763 & -3.2241 & -3.4589 & -0.3342 & \multirow{3}{*}{9.36} \\
\hline & Overshoot $\left(\mathrm{O}_{\mathrm{sh}} \times 10^{-3}\right)$ & 12.0856 & 3.3721 & 3.2759 & 3.5216 & 3.9896 & 0.4856 & \\
\hline & Settling time $\left(T_{s}\right)$ & 37.04 & 46.54 & 45.48 & 51.82 & 49.71 & 49.71 & \\
\hline
\end{tabular}




\section{CONCLUSION}

In this work, a maiden endeavor is made to recommend a comparative analysis between PID and FPID controller for power/frequency stabilization of single and multi-area thermal power systems. A hybrid ADECRPSO algorithm is proposed by blending the benefits of alopex based DE and craziness based PSO algorithms. The acceptability of proposed algorithm is demonstrated over DE, PSO, CRPSO, and ADE algorithms. The basic purpose of implementation of the controller and optimization technique is to enhance the quality, reliability, and stability of the supply power to the consumers. To improve the performance of the system with same controller, the improvement of optimization technique is an indispensable factor.

A step load variation of $10 \%$ is implemented to observe the improvement of the deviation of frequency and power of the thermal-hydro-diesel power system. A comparative analysis of system performance with DE, PSO, CRPSO, ADE, and ADECRPSO algorithms optimized FPID controller is portrayed to substantiate the capability of ADECRPSO based FPID controller to yield better performance. The supremacy of FPID controller over ADECRPSO based PID controller is interpreted and it is observed that PSO based FPID is also better than ADECRPSO based PID controller. The proposed approach is substantiated in real time system (OPAL RT OP5600) and the robustness of the system is observed by implementing load variation in area-1.

Further, the analysis is extended to a two-area thermal-hydro power system with load disturbance of 1\% in area-1. Hybrid ADECRPSO algorithm is ratified as an admirable technique to pursuit the PID controller gains in thermal-hydro system in comparison with hGGSA-PS and hFA-PS algorithms. The proposed hybrid ADECRPSO optimized FPID controller is validated adorably with ASOS and BFOA optimized FPID controller. To substantiate the supremacy to handle non-linearity, the proposed approach is implemented in a complex thermal-hybrid power system with physical constraints. Finally, the proposed ADECRPSO algorithm and FPID controller are observed as admirable approaches to yield better performance.

\section{APPENDIX-1 (Power system Parameters)}

$\mathrm{T}_{\mathrm{g}}=0.08 ; \mathrm{T}_{\mathrm{t}}=0.3 ; \mathrm{T}_{\mathrm{r}}=10 ; \mathrm{K}_{\mathrm{P} 1}=\mathrm{K}_{\mathrm{P} 2}=120 ; \mathrm{T}_{\mathrm{P} 1}=\mathrm{T}_{\mathrm{P} 2}=20 ; \mathrm{R}_{1}=\mathrm{R}_{2}=\mathrm{R}_{3}=2.4 ; \mathrm{B}_{1}=\mathrm{B}_{2}=0.425 ; \mathrm{T}_{\mathrm{w}}=1 ; \mathrm{T}_{1}=41.6 ;$ $\mathrm{T}_{\mathrm{R}}=5 ; \mathrm{T}_{2}=0.513 ; \mathrm{K}_{\text {Diesel }}=16.5 ; \mathrm{a}_{12}=-1$;

\section{APPENDIX-2 (Assumptions for optimization technique)}

$$
\mathrm{F}=0.65 ; \mathrm{CR}=0.35 ; \mathrm{V}_{\text {Craziness }}=0.0001 ; \mathrm{P}_{\mathrm{cr}}=0.3 ; \mathrm{C}_{1}=2.05 ; \mathrm{C}_{2}=2.05 ;
$$

\section{APPENDIX-3 (Hydro-thermal power system parameters)}

$$
\mathrm{B}_{1}=0.425 ; \mathrm{B}_{2}=0.425 ; \mathrm{R}_{1}=2 ; \mathrm{R}_{2}=2.4 ; \mathrm{T}_{\mathrm{h} 1}=0.08 ; \mathrm{T}_{\mathrm{t} 1}=0.3 ; \mathrm{K}_{\mathrm{P} 1}=\mathrm{K}_{\mathrm{P} 2}=100 ; \mathrm{T}_{\mathrm{P} 1}=\mathrm{T}_{\mathrm{P} 2}=20 ; \mathrm{k} 1=1 ; \mathrm{T}_{1}=48.7 ; \mathrm{T}_{\mathrm{w}}
$$
$=1 ; \mathrm{T}_{2}=0.513 ; \mathrm{T}_{\mathrm{r}}=5 ; \mathrm{T}_{12}=0.0707 ; \mathrm{a}_{12}=-1 ; \Delta \mathrm{P}_{\mathrm{D} 1}=0.01 ; \Delta \mathrm{P}_{\mathrm{D} 2}=0 ;$

\section{APPENDIX-4 (Thermal-hybrid power system)}

$\mathrm{B}=0.425 ; \mathrm{R}=2.4 ; \mathrm{T}_{\mathrm{SG}}=0.08 ; \mathrm{T}_{\mathrm{T}}=0.3 ; \mathrm{K}_{\mathrm{R}}=0.5 ; \mathrm{T}_{\mathrm{R}}=10 ; \mathrm{T}_{12}=\mathrm{T}_{23}=\mathrm{T}_{13}=0.0867 ; \mathrm{K}_{\mathrm{PS}}=120 ; \mathrm{T}_{\mathrm{PS}}=20 ; \mathrm{K}_{1}=0.85 ;$ $\mathrm{K}_{2}=0.095 ; \mathrm{K}_{3}=0.92 ; \mathrm{K}_{\mathrm{IB}}=0.03 ; \mathrm{T}_{\mathrm{IB}}=26 ; \mathrm{T}_{\mathrm{RB}}=6.9 ; \mathrm{T}_{\mathrm{F}}=10 ; \mathrm{T}_{\mathrm{D}}=0 ; \mathrm{C}_{\mathrm{B}}=200 ; \mathrm{K}_{\mathrm{SPG}}=1 ; \mathrm{T}_{\mathrm{SPG}}=1.8 ; \mathrm{K}_{\mathrm{WPG}}=1 ; \mathrm{T}_{\mathrm{WPG}}=1.5 ; \mathrm{K}_{\mathrm{FC}}$ $=0.01 ; \mathrm{T}_{\mathrm{FC}}=4 ; \mathrm{K}_{\mathrm{AE}}=0.002 ; \mathrm{T}_{\mathrm{AE}}=0.5 ; \mathrm{K}_{\mathrm{BESS}}=-0.0033 ; \mathrm{T}_{\mathrm{BESS}}=0.01 ; \mathrm{K}_{\mathrm{DE}}=0.0033 ; \mathrm{T}_{\mathrm{DE}}=2 ; \mathrm{a}_{12}=-1 / 3 ; \mathrm{a}_{13}=-1 / 5 ; \mathrm{a}_{23}$ $=-3 / 5$; 


\section{REFERENCES}

Arya, Y. \& Kumar, N. 2017. Design and analysis of BFOA-optimized fuzzy PI/PID controller for AGC of multi-area traditional/ restructured electrical power systems. Soft Computing, 21(21), Pp. 6435-6452.

Chown, G.A. \& Hartman, R.C. 1997. Design and experience with a fuzzy logic controller for automatic generation control (AGC), IEEE Trans. Power Syst., 13(3), Pp. 352-357.

Cohn, N. (1956). Some aspects of tie-line bias control on interconnected power. Transactions of the American institute of electrical engineers. Part III: power apparatus and systems, 75(3), Pp. 1415-1436.

Dash, P., Saikia, L.C. \& Sinha, N. 2014. Comparison of performances of several Cuckoo search algorithm based 2DOF controllers in AGC of multi-area thermal system. Int. J. Electr. Power Energy Syst., 55, Pp. 429-436.

Dash, P., Saikia, L.C. \& Sinha, N. 2015. Automatic generation control of multi area thermal system using Bat algorithm optimized PD-PID cascade controller. Int. J. Electr. Power Energy Syst., 68, Pp. 364-372.

Dash, P., Saikia, L.C. \& Sinha, N. 2016. Flower Pollination Algorithm Optimized PI-PD Cascade Controller in Automatic Generation Control of a Multi-area Power System. Int. J. Electr. Power Energy Syst., 82, Pp. 19-28.

Fosha, E. 1970. Megawatt-Frequency Control Multi area Electric Energy Systems. 4, Pp. 556-563.

Ghoshal, S.P. 2004. Optimizations of PID gains by particle swarm optimizations in fuzzy based automatic generation control. Electr. Power Syst. Res., 72(3), Pp. 203-212.

Gozde, H., Cengiz Taplamacioglu, M. \& Kocaarslan, İ. 2012. Comparative performance analysis of Artificial Bee Colony algorithm in automatic generation control for interconnected reheat thermal power system. Int. J. Electr. Power Energy Syst., 42(1), Pp. 167-178.

Guha, D., Roy, P.K. \& Banerjee, S. 2016. Load frequency control of interconnected power system using grey Wolf optimization. Swarm Evol. Comput., 27, Pp. 97-115.

Kar, R., Mandal, D., Mondal, S. \& Ghoshal, S.P. 2012. Craziness based Particle Swarm Optimization algorithm for FIR band stop filter design, Swarm Evol. Comput., 7, Pp. 58-64.

Kennedy, J. \& Eberhart, R. 1995. Particle swarm optimization. Neural Networks, Proceedings., IEEE Int. Conf., 4, Pp. 19421948.

Khadanga, R.K. \& Kumar, A. 2017. Hybrid adaptive "gbest"-guided gravitational search and pattern search algorithm for automatic generation control of multi-area power system. IET Generation, Transmission \& Distribution, 11(13), Pp. 3257-3267.

Khodabakhshian, A. \& Hooshmand, R. 2010. A new PID controller design for automatic generation control of hydro power systems. Int. J. Electr. Power Energy Syst., 32(5), Pp. 375-382.

Kumar, P. \& Kothari, D.P. 2005. Recent philosophies of automatic generation control strategies in power systems. IEEE transactions on power systems, 20(1), Pp. 346-357.

Kundur, P., Balu, N.J. \& Lauby, M.G. 1994. Power system stability and control. New York: McGraw-hill, 7.

Leon, M. \& Xiong, N. 2017. Alopex-based mutation strategy in differential evolution. In 2017 IEEE Congress on Evolutionary Computation (CEC), Pp. 1978-1984.

Nanda, J., Mishra, S. \& Saikia, L.C. 2009. Maiden application of bacterial foraging-based optimization technique in multiarea automatic generation control. IEEE Trans. Power Syst., 24(2), Pp. 602-609.

Nayak, J.R., Pati, T.K., Sahu, B.K. \& Kar, S.K. 2015a. Fuzzy-PID controller optimized TLBO algorithm on automatic generation control of a two-area interconnected power system. IEEE Int. Conf. Circuit, Power Comput. Technol. ICCPCT, Pp. 1-4.

Nayak, J.R., Sahu, B.K. \& Pati, T.K. 2015b. Load frequency control of a two-area non-reheat thermal system using Type-2 Fuzzy system optimized DEPSO algorithm. in 2015 International Conference on Energy, Power and Environment: Towards Sustainable Growth, ICEPE, 2(1), pp. 1-5.

Nayak, J.R., Shaw, B. \& Sahu, B.K. 2017. Load frequency control of hydro-thermal power system using fuzzy PID controller optimized by hybrid DECRPSO algorithm. International Journal of Pure and Applied Mathematics, 114(9), Pp. 147-155.

Nayak, J.R. \& Shaw, B. 2018a. Application of group hunting search optimized cascade PD-fractional order PID controller in interconnected thermal power system. Trends in Renewable Energy, 4(3), Pp. 22-33.

Nayak, J.R., Shaw, B., Das, S. \& Sahu, B.K. 2018b. Design of MI fuzzy PID controller optimized by Modified Group Hunting 
Search algorithm for interconnected power system. Microsystem Technologies, 24(9), Pp. 3615-3621.

Nayak, J.R., Shaw, B. \& Sahu, B.K. 2018c. Application of adaptive-SOS (ASOS) algorithm based interval type-2 fuzzy-PID controller with derivative filter for automatic generation control of an interconnected power system. International Journal of Engineering Science and Technology, 21(3), Pp. 465-485.

Panda, S., Mohanty, B. \& Hota, P.K. 2013. Hybrid BFOA-PSO algorithm for automatic generation control of linear and nonlinear interconnected power systems. Applied Soft Computing, 13(12), Pp. 4718-4730.

Rout, U.K., Sahu, R.K. \& Panda, S. 2013. Design and analysis of differential evolution algorithm based automatic generation control for interconnected power system. Ain Shams Engineering Journal, 4(3), Pp. 409-421.

Saha, S.K., Kar, R., Mandal, D. \& Ghoshal, S.P. 2013. An efficient craziness based particle swarm optimization technique for optimal IIR filter design. In Transactions on Computational Science XXI. Springer, Berlin, Heidelberg, Pp. 230-252.

Sahu, B.K., Pati, S., Mohanty, P.K. \& Panda, S. 2015. Teaching-learning based optimization algorithm based fuzzy-PID controller for automatic generation control of multi-area power system. Applied Soft Computing, 27, Pp. 240-249.

Sahu, B.K., Pati, S. \& Panda, S. 2014. Hybrid differential evolution particle swarm optimisation optimised fuzzy proportionalintegral derivative controller for automatic generation control of interconnected power system. IET Generation, Transmission \& Distribution, 8(11), Pp. 1789-1800.

Sahu, B.K., Pati, T.K., Nayak, J.R., Panda, S. \& Kar, S.K. 2016. A novel hybrid LUS-TLBO optimized fuzzy-PID controller for load frequency control of multi-source power system. International Journal of Electrical Power \& Energy Systems, 74, Pp. 58-69.

Sahu, R.K., Panda, S. \& Sekhar, G.C. 2015a. A novel hybrid PSO-PS optimized fuzzy PI controller for AGC in multi area interconnected power systems. International Journal of Electrical Power \& Energy Systems, 64, Pp. 880-893.

Sahu, R.K., Panda, S. \& Padhan, S. 2015b. A hybrid firefly algorithm and pattern search technique for automatic generation control of multi area power systems. International Journal of Electrical Power \& Energy Systems, 64, Pp. 9-23.

Sahu, R.K., Panda, S. \& Padhan, S. 2015c. A novel hybrid gravitational search and pattern search algorithm for load frequency control of nonlinear power system. Applied Soft Computing, 29, Pp. 310-327.

Sahu, R.K., Panda, S., Rout, U.K. \& Sahoo, D.K. 2016. Teaching learning based optimization algorithm for automatic generation control of power system using 2-DOF PID controller. International Journal of Electrical Power \& Energy Systems, 77, Pp. 287-301.

Sanki, P. \& Basu, M. 2018. New approach in two-area interconnected AGC including various renewable energy sources using PSO. Turkish Journal of Electrical Engineering \& Computer Sciences, 26(3), Pp. 1491-1504.

Shabani, H., Vahidi, B. \& Ebrahimpour, M. 2013. A robust PID controller based on imperialist competitive algorithm for loadfrequency control of power systems. ISA transactions, 52(1), Pp. 88-95.

Storn, R. \& Price, K. 1997. Differential evolution-a simple and efficient heuristic for global optimization over continuous spaces. Journal of global optimization, 11(4), Pp. 341-359.

Tzanakou, E., Michalak, R. \& Harth, E. 1979. The alopex process: visual receptive fields by response feedback. Biological Cybernetics, 35(3), Pp. 161-174.

Upadhyay, P., Kar, R., Mandal, D. \& Ghoshal, S.P. 2014. Craziness based particle swarm optimization algorithm for IIR system identification problem. AEU-International Journal of Electronics and Communications, 68(5), Pp. 369-378.

Yeşil, E., Güzelkaya, M. \& Eksin, I. 2004. Self tuning fuzzy PID type load and frequency controller. Energy Conversion and Management, 45(3), Pp. 377-390.

Zadeh, L.A. 1965. Fuzzy sets. Information and control, 8(3), Pp. 338-353.

Zhang, W.J. \& Xie, X.F. 2003. DEPSO: hybrid particle swarm with differential evolution operator. IEEE International Conference on Systems, Man and Cybernetics, 4, pp. 3816-3821. 


\title{
هجين الـ Alopex المبني على خوارزمية الـ DECRPSO المحسن لتحكم PID الغامض لل AGC
}

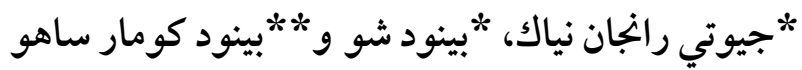

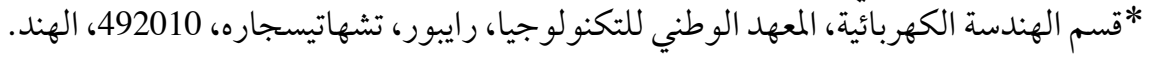

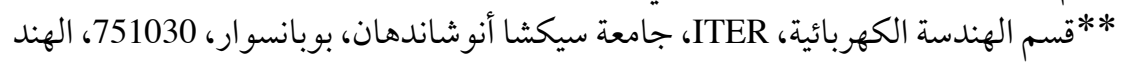

\section{الخلاصة}

يفضل هذا البحث ألوبيكس المستندة إلى خوارزمية تحسين الجسيمات المستندة إلى التطور التفاضلي التجزعي المستندة

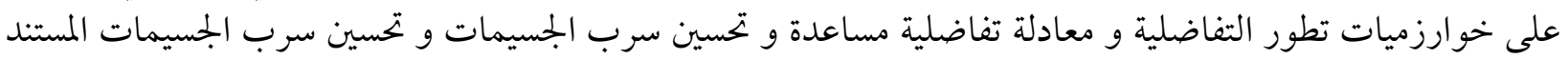

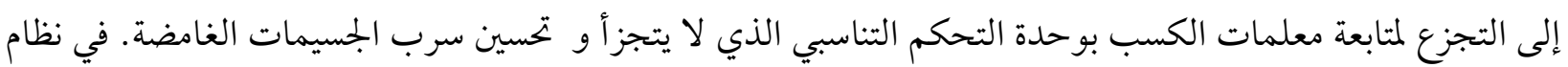

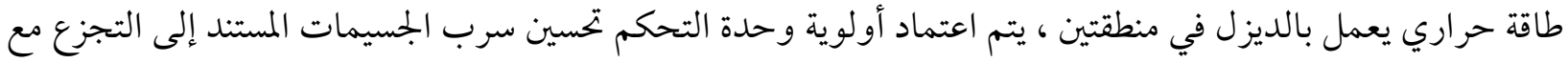

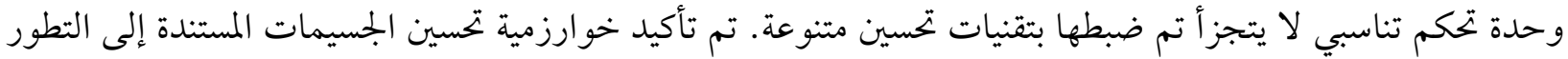

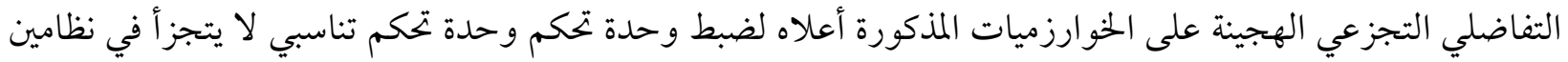

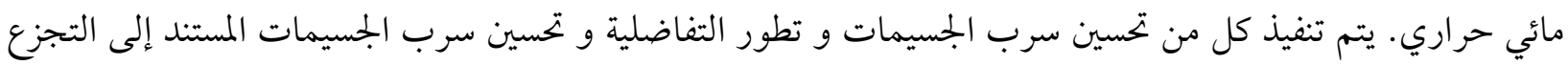

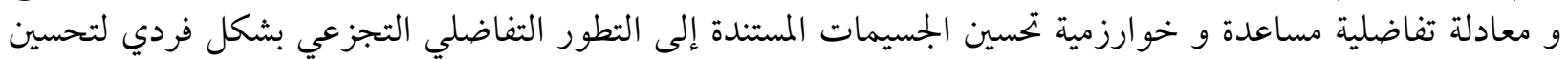

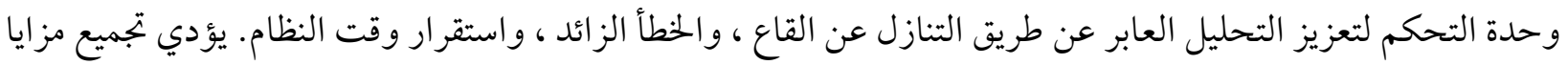

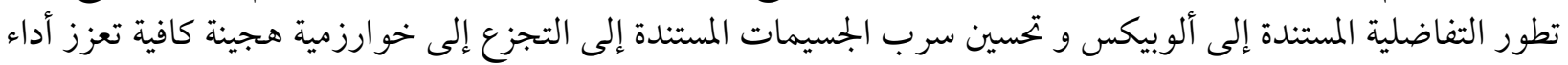

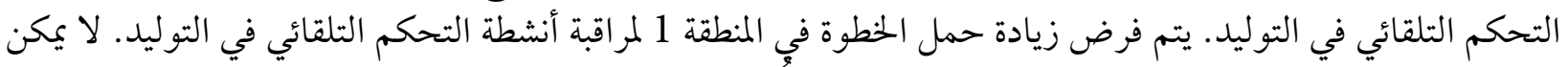

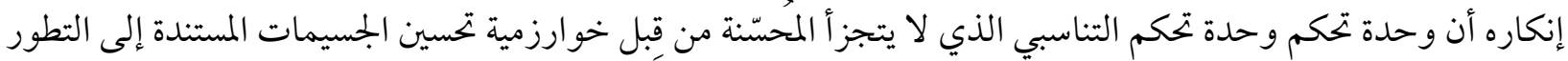

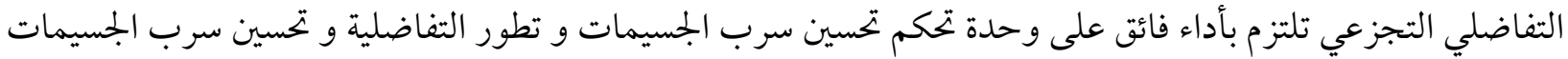

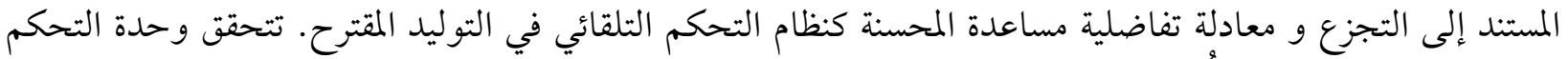

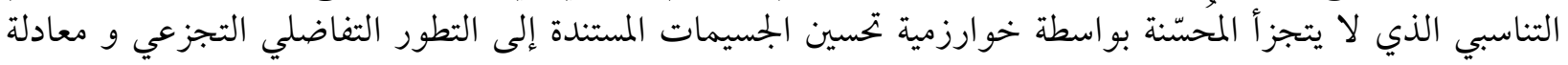

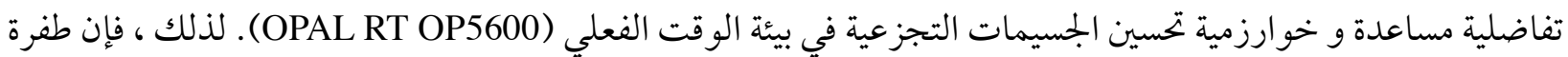

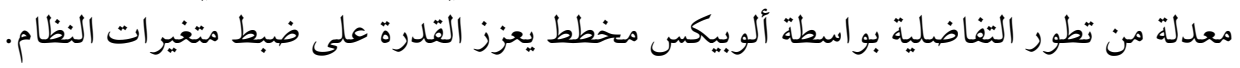

